\title{
DETECTING AND
}

INTERPRETING

FINANCIAL STRESS

\section{IN THE EURO AREA}

by Marianna Blix Grimaldi 


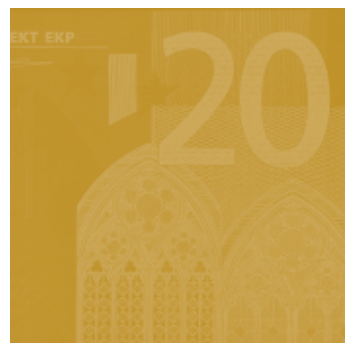

\title{
WORKING PAPER SERIES
}

NO 1214 I JUNE 2010

\section{DETECTING AND INTERPRETING \\ FINANCIAL STRESS IN \\ THE EURO AREA'}

\author{
by Marianna Blix Grimaldi²
}
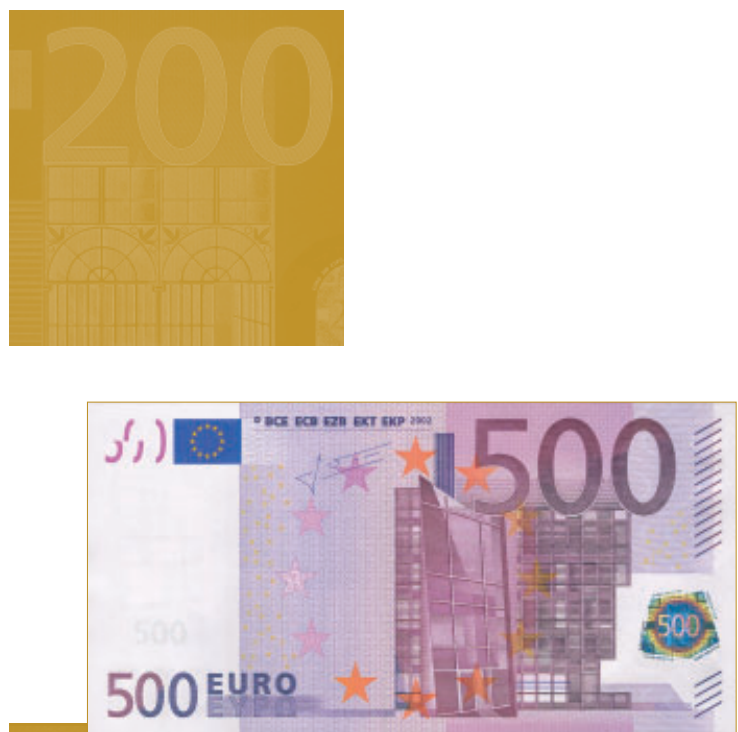

In 2010 all ECB

publications

feature a motif

taken from the

NOTE: This Working Paper should not be reported as representing the views of the European Central Bank (ECB).

The views expressed are those of the author and do not necessarily reflect those of the $E C B$.

This paper can be downloaded without charge from http://www.ecb.europa.eu or from the Social Science Research Network electronic library at http://ssrn.com/abstract_id $=1622165$.

I The paper was written while I was visiting the Capital Markets and Financial Structure Division, European Central Bank. I am grateful to Mårten Blix, Matthieu Bussière, Paul De Grauwe, Carsten Detken, Francesco Drudi, Marcel Fratzscher, Manfred Kremer, Laurent Maurin,

Philippe Moutot, John Roberts, Bernd Schnatz, Dawid Zochowski, as well as participants at various seminars at the ECB for helpful comments. I would also like to thank Agne Subelyte for help with data, Robert Wiklund for help with programming and Tracey Green for help with selecting financial press articles and news. The opinions expressed in the paper are those of the author and need not reflect those of the Riksbank. In particular, the word search performed in no way should be interpreted as an indicator of the ECB's communication. 2 Sveriges Riksbank, I 3737 Stockholm, Sweden, 
(C) European Central Bank, 2010

Address

Kaiserstrasse 29

60311 Frankfurt am Main, Germany

Postal address

Postfach 160319

60066 Frankfurt am Main, Germany

Telephone

+496913440

Internet

http://www.ecb.europa.eu

Fax

+496913446000

All rights reserved.

Any reproduction publication and reprint in the form of a differen publication, whether printed or produced electronically, in whole or in part, is permitted only with the explicit written authorisation of the ECB or the author.

Information on all of the papers published in the ECB Working Paper Series can be found on the ECB's website, http://www. ecb.europa.eu/pub/scientific/wps/date/ html/index.en.htm

ISSN 1725-2806 (online) 


\section{CONTENTS}

Abstract 4

Non-technical summary 5

1 Introduction 7

2 Constructing the Financial Stress Indicator (FSI) 8

2.1 On defining stress 8

2.2 Constructing a list of stressful events $\quad 10$

2.3 Selecting individual indicators 20

2.4 Aggregating information

from the underlying variables

2.5 Combining the underlying variables into a single indicator

3 The FSI: a contingent indicator

3.1 Insights from behavioural finance

3.2 Computing the FSI

3.3 FSI compared to the VSTOXX and its noise/signal content

3.4 Robustness properties

4 Predicting future stress - the FSI as leading indicator?

5 Conclusion

Appendices

References 


\begin{abstract}
There is a need to find better models and indicators for large disruptive events, not least in order to be more prepared and mitigate their effects. In this paper we take a step in this direction and discuss the performance of a financial stress indicator with a specific focus on the euro area. As far as we know, our indicator is the first attempt to develop an indicator of financial stress with a specific focus on the euro area. It is also the first to exploit the information contained in central bank communication to help measure stress in financial markets. For use in real time, the indicator is able to efficiently extract information from an otherwise noisy signal and provide information about the level of stress in the markets.
\end{abstract}

JEL codes: E44, E50, G10

Key words: Financial stress, central bank communication, logit distribution, leading indicator, behavioural finance. 


\section{Non-technical summary}

There is a need to find better models and indicators for large disruptive events, not least in order to be more prepared and mitigate their effects. In this paper we take a step in this direction by constructing a financial stress indicator. As far as we know, our indicator is the first attempt to develop an indicator of financial stress with a specific focus on the euro area. It is also the first to exploit the information contained in central bank communication to help measure the level of stress in financial markets.

It is important to note that financial stress is related to - but is not identical - to market volatility. For example, there can be a lot of volatility in the market when new unexpected information arrives in a flow but this need not imply that there is stress in the market. On the opposite end, with high financial spreads signifying something amiss, for example that no trade is taking place, the volatility might be very low but stress very high. The Financial Stress Indicator presented in this paper uses statistical techniques and judgement to pin down an indicator that is much richer in nuance than simple measures of volatility. In fact, some volatility based measures (such as the VSTOXX) even failed to pick up the onset of the financial crisis in 2007.

The 2007-2009 financial crisis is the largest and most significant time of financial stress in modern times, but even if its magnitude exceeds others it is not the only one. Both empirical research and anecdotal evidence suggest that rare events with potentially large impact play a more important role than often accorded to them by the financial literature. Other prominent examples are the dot.com bust, Y2K, the accounting irregularities associated with some firms such as Arthur Anderssen, Enron, and Worldcom as well as the Russian sovereign debt default in 1998. The events have different causes and effects, but share the trait of being, by and large, surprises that caused considerably disruptions to the markets. In recent popular and academic works, rare events of this calibre have been labelled "Black-Swans", denoting a disruptive event that seems "so unlikely that it only seems possible after it has occurred", see Taleb (2007) and Taylor and Williams (2008). But also large events but somewhat less extreme are of interest if they cause disruptions in the markets.

We know now, and have indeed known for some time, that these events occur too often and are too disruptive to be explained fully by mainstream financial models, especially those that espouse normally distributed shocks in the system. One calculation by Mandelbrot (2008) estimates that in classical models a shock, such as the recent one, should 
occur only one time in a billion years. Clearly, having at least two such events within a century shows that the risks of rare and disruptive events and their effects are underestimated in mainstream models of finance.

In this paper we do not take a stance on the theoretical challenges posed by rare disruptive events. We note that there are different research agendas that recognise the challenges to standard models, such as models from behavioural finance as well as attempts to build in frictions and imperfections into neo-classical models. For our purposes it is enough to note that rare events are overrepresented in the data and that is desirable to measure them better with a view of being able to detect changes in the level of financial stress earlier, and, hopefully, be able to do something to alleviate the effects.

The methodology in this paper is simple. We use quantitative methods to extract information about the level of stress from an otherwise set of noisy financial markets data. We use the information from the published ECB Monthly Bulletins to identify periods of stress (as measured by the number of times that certain a priori specified key words occur). The Monthly Bulletins have several advantages in this regard. They capture movements in the economy, are widely distributed and read and do not reflect any vested or commercial interests.

The signal extracted is from key financial markets data available on high frequency. This means the indicator can be used in real time to extract information about the level of stress in the markets. We show that the indicator has a good performance in detecting the build-up of disruptive events while producing few false positives. While a full-scale rollingregression type evaluation is not performed, a more simple out-of-sample evaluation shows that the results are robust.

How should the results be interpreted? An increased signal of stress from the indicator is an argument in favour of applying more judgement to standard forecasting tools and for taking extra care to monitor financial markets developments. In particular, linear econometric models may not be the most appropriate tools when "rare events" are affecting the markets. 


\section{Introduction}

In this paper we take a quantitative approach to investigate financial stress and construct an indicator for the euro area, improving on the indicator proposed by Nelson and Perli (2006) for the US. In particular, we use a larger and more informative dataset of individual variables and gauge performance both by estimating the indicator out-of-sample as well as using the indicator as a measuring rod against other well known measures of economic conditions.

The challenge for a financial stress indicator (hereafter FSI) is, on the one hand, to be able to accurately and timely signal times of stress while, on the other, to not have "too many" false positives and "cry wolf". The disruptive events pose special econometric challenges as they occur seldom but have big impact. In other words, there are few but important data points on which to base inference. In some econometric work it may be appropriate to treat such events as outliers, for example by using dummy variables, but arguably this poses questions about how useful such estimates are in times of turmoil. In particular, linear econometric models may be less informative the further out in the tails of the distribution events occur. Simple linear regressions may be misleading when drawing inferences about rare events as abundant empirical research has shown that the tails of distributions are often thicker than had they been drawn from a normal or symmetric distribution.

Aside from difficulties in estimation and interpretation, probabilities of large bad events had a bit of an uphill struggle before the 2007-2009 financial crisis when the "mood" was less open to suggestions that good times may not last, not least witnessed by the work under the rubric of "irrational exuberance" in notable contributions prior to the financial crisis by Shiller (2000) and also expressed in several speeches by Alan Greenspan when he was Chairman of the Federal Reserve. The 2007-2009 financial crisis has shown in no uncertain terms that rare events occur more often than classical models based on normality would indicate. Moreover, events, such as LTCM, the dot.com crash and 9/11 highlight that disruptive events are, unfortunately, not as rare as we would like. More importantly, our ability to detect them in real time, or preferably before they occur, leaves much to be desired.

Here we develop an indicator that distinguishes between tranquil periods and acute periods of stress. It can be used to:

1) assess the current state of the financial markets in the euro area in a timely way, and, therefore, it provides a timely snapshot of contemporaneous stress in the financial 
markets;

2) relate its signal to other information obtained from models and other sources.

The use of the FSI as a complement to other information is explored more fully below, but the information content to assess the real time sentiment in the market is a use in its own right. It is well known from assessing business cycles that the current state of the economy, for example as measured by output gaps, is measured with considerable uncertainty. This also holds true for measuring asset price bubbles. In the same vein, the FSI can convey information about the current state of the markets, allowing gauging the severity of financial events as they transpire and yet summarising a lot of information in a single, simple-to-use indicator.

While formal models that allow for extreme events (or 10-sigma events as expressed by Nobel Prize winner M. Scholes when LTCM collapsed) exist, they are not necessarily easy to take to the data or to apply. The FSI, on the other hand, does not rest firmly on an optimising model from mathematical finance but is relatively straightforward to use. This makes it important to investigate the performance of the FSI in a variety of dimensions, and this is reflected in the organisation of the paper. Section 2 describes the rationale for the FSI and how we construct it by aggregating market-based variables and extracting information from the ECB Monthly Bulletins. Section 3 discusses how to compute the FSI, and how it compares to other known indices such as the VSTOXX as well as robustness properties. Section 4 deals with the use of the FSI as a forward indicator. Although it is not designed for this purpose, it turns out to have some good properties in this regard. The last section concludes.

\section{Constructing the Financial Stress Indicator (FSI)}

\subsection{On defining stress}

The financial literature does not provide a precise definition of financial stress but, in general, stress is the product of vulnerable markets and of shocks that can be either exogenous or, more likely, endogenous. For the purposes of this paper, we can think of the level of stress as being determined by the interaction between financial vulnerabilities and the size of shocks. The more fragile financial conditions are, i.e. the more vulnerable markets are, the more likely a shock is to result in stress. In extreme cases, either when the shock is very large or when financial conditions are very weak, a shock can result in a crisis and extreme stress. 
We derive a measure of financial stress in the form of an indicator (FSI). Therefore our approach is related to the literature on financial (currency and banking) crises and to the literature on early warning signals. However, compared to the majority of studies in these areas, the FSI has several attractive features. First, it is based on real time-high frequency data. Second, it takes a broader perspective as the aim is the assessment of the level of stress of the overall financial system at any point in time. Third, it belongs to a very small group of indicators constructed for developed economies. Related papers are Illing and Liu (2006) who develop a financial stress index for the Canadian economy, Nelson and Perli (2006) who construct one for U.S. economy and more recently Cardarelli, Elekdag and Lall (2009) who analyse the experience from episodes of financial stress and economic cycles among 17 advanced economies over the past three decades.

There are also few measures of stress or, more generally, of market conditions provided by market data providers and private research institutions. For example Bloomberg has its own financial conditions index which is based on yield spreads and measures of money, bond and stock markets. The OECD publishes a composite leading indicator of economic activity for the OECD countries while the CEPR has computed a real time indicator of expansion and contraction of the economic cycle, called the €coin. ${ }^{1}$ Both the CEPR and OECD indices may be related to changes in financial conditions. As far as we know, the FSI is the first attempt to develop an indicator of financial stress with a specific focus on the euro area.

It is also the first indicator to exploit the information contained in central bank communication to help measure the level of stress in financial markets. While becoming increasingly richer, the literature on central bank communication has remained focus on either predicting future asset prices (for example, see Lucca and Trebbi (2009)) or on addressing transparency issues (see, for example, Bligh and Hess (2009)).

We use a three steps procedure to compute the FSI. First, we select a list of "stressful" events, then we construct a measure of stress, finally we connect the previous two by using a logit model.

\footnotetext{
${ }^{1}$ The $€$ coin is computed by CEPR as contingent indicator of economic conditions. It has a monthly frequency. See www.cepr.com for details.
} 


\subsection{Constructing a list of stressful events}

Because of the lack of an agreed upon definition of financial stress, it is not entirely unproblematic to identify financial stress periods. In addition, dating financial stress periods is also not straightforward as the literature provides several methods to date financial crises but not stress. One method of dating is provided in Illing and Liu (2006). Another approach is provided in Bussière and Fratzscher (2006), who also take into account post-crisis periods, so that the crisis variable takes value of zero in tranquil periods, one before and during the crisis, and two in the post-crisis period. Lestano, Jacobs and Kuper (2003) distinguish between currency crisis, banking crisis and debt crisis. For currency crises, they use a variety of determinants, while they identify banking and debt crisis with the help of IMF reports and central banks publications. Goldstein, Kaminsky and Reinhart (2000) use a qualitative approach to identify banking crises which focuses on events, for example the occurrence of bank runs. To identify events they rely on existing studies of banking crises and on historical narratives.

Since there is no commonly agreed list of stressful events in the euro area, one way to proceed is to create a list that matches well-defined criteria. We draw from the existing literature by combining information in a qualitative-quantitative approach, inspired by studies in other fields such as linguistic and fine arts that blend informal methods with quantitative ones.

Our method is as follows. First, we use judgement to identify periods of stress around episodes of financial tensions, for example $\mathrm{Y} 2 \mathrm{~K}$, the dot.com bubble, the Worldcom accounting irregularity and the recent global financial crisis (see table 1). The selected episodes are events that have received considerable exposure in the financial press and in the markets. $^{2}$ While there is some element of subjectivity involved, the episodes correspond closely to events discussed in other papers and would be classified as periods of stress under a wide range of classification schemes. ${ }^{3}$ In order to be able to pin down as precisely as possible the starting and the ending periods, we draw on selected financial press as well as the ECB Monthly Bulletins and in particular on the editorial and the sections that are dedicated to

\footnotetext{
${ }^{2}$ See, for example, The Economist $15^{\text {th }}$ July 2002, $28^{\text {th }}$ Nov 2002, $3^{\text {rd }}$ June 2004 and $21^{\text {st }}$ October 2004. See also appendix 1.

${ }^{3}$ See, for example, Chulia, Climent, Soriano and Torro (2009).
} 
financial markets. ${ }^{4}$ In so doing, we extract information related to the direction of markets, the overall economy as well as the "mood" of the markets.

Table 1. Periods of stress

\begin{tabular}{ll}
\hline Y2K & Jul 99 - Jan 00 \\
dot.com & Mar 00 - Dec 00 \\
$9 / 11$ & Sep 01 - Nov 01 \\
Corporate scandals & Jun 02 - Aug 02 \\
Iraq war & Mar 03 - May 03 \\
Madrid bombings & March 04 \\
Heightened uncertainty/Oil prices increases & Jun 04 - Dec 04 \\
London bombings & July 05 \\
Global financial crisis & Aug 07 - Jun 09 \\
\hline \hline
\end{tabular}

In table 1 we show periods of heightened uncertainty and tensions. Although the periods are carefully chosen, there is an inevitable element of subjectiveness in the selection that we try to keep as well-defined and limited as possible. Subjective is not the same as arbitrary, however, and we will see further below the advantages of this approach. In addition, we run a "word search" over the whole text in each ECB's Monthly Bulletin in order to systematically identify nuances in communication. ${ }^{5}$

What is the value added of using the Monthly Bulletins in this way? Do they not already contain an assessment that reflects the financial and real economy? What is the point of extracting something that is already using measured language and from a source that does not have any vested commercial interests? If we were interested in estimating parameters in a model, there could potentially be an identification issue as both financial markets and the ECB's assessment in some ways reflect what we are aiming to measure. But Lucca and

${ }^{4}$ Extracting information from Monthly Bulletins has also been done by Gerlach (2004) and Rosa and Verga(2005).

${ }^{5}$ Ideally we would have liked to run a "word search" also on text from other sources but the level of noise has proved to be too high for a meaningful exercise. 
Trebbi (2009) and Bligh and Hess (2009) show that the flow of information from central banks is relevant for the movements and for the volatility of financial markets. ${ }^{6}$ In addition, Rosa and Verga (2005) have shown that the Monthly Bulletins contain complementary information to that of the markets that has a value in its own right. ${ }^{7}$ Moreover, we are not interested in identification of parameters per se; we are interested in extracting information on financial stress that has good signal-to-noise properties. Thus, ultimately the performance of the FSI should be measured on how well it extracts information and how much it helps us to clarify the often conflicting signals from different sources.

The Monthly Bulletins have another advantage as well. It is true that some other sources can provide information at higher frequency, such as weekly or daily data. Unfortunately, the higher the frequency the stronger the noise in the signal tends to be. And even when noise can be efficiently filtered away, filters contain their own set of problems. Overall, monthly frequency provides a good balance between the need for timely information and the potential risk of overreacting to noise.

The word-search in the ECB's Monthly Bulletins was conducted as follows. We searched for words whose meaning is commonly associated with stress, tensions, vulnerabilities or general weakness in the financial markets as well as in the overall economy. In order to avoid tilting the results, we also include several words with positive meaning, such as "recovery", "robust" and "favourable". Appendix 1 shows the complete list of selected positive and negative words. ${ }^{8}$ Notwithstanding that the choice of words is somewhat subjective and it is difficult to have clear-cut words of positive (no-stress) or negative (stress) meaning, the chosen words are selected with the intent to minimise possible misinterpretation. For example, the noun risk, depending on the context, could have a positive nuance if risks were lower or negative if risk were higher. Nonetheless, when the word risk appears it means that there are risks and therefore there is (at least some) stress in the economy. There may

${ }^{6}$ In particular, Lucca and Trebbi (2009) attempt to measure central bank communication about future interest rate decisions based on information from the Internet and news sources while trying to control for "semantic orientation", i.e. the intensity and the direction of meaning. They apply the methodology to the statements released by the Federal Open Market Committee (FOMC) after its policy meetings. Bligh and Hess (2009) try to establish the impact of Greenspan's speeches, testimonies and FOMC statements on financial market variables by applying computerised content analysis.

${ }^{7}$ Although the FSI-word search extracts information from ECB-publications, it should not be interpreted as an indicator of ECB communication.

${ }^{8}$ We ran a pre-selection on a larger pool of words in order to pin down a workable number of words. We require that the selected words appear at least once in the Monthly Bulletins for each year, with the exception of the word crisis. In addition, in case of synonyms we choose the word that appears more often. 
remain cases in which the semantic orientation of the sentence may partially bias the results of the word-search. ${ }^{9}$ But, in general terms, semantic orientation issues, as also highlighted by the analysis of Lucca and Trebbi (2009), are more relevant for the public dialogue than for the written language of a central bank.

To illustrate the results of the word-search for the year 2007, when the global financial crisis started, see table 2 . The complete results for all years are shown in appendix 2 . To capture variations of the chosen words, we use a wildcard in the search algorithm, which in table 2 is denoted by a "*". To set a benchmark for the stress signal, we first count the number of negative (positive) words for each month, then we compute the average number of negative (positive) words. In order to avoid distortions due to the different lengths of the Monthly Bulletins, the average of negative (positive) words is weighted by the number of pages. ${ }^{10}$ Third, we specify a threshold such that when the weighted average of negative (positive) words is above such a threshold it signals a period of high (low) stress and when below the threshold it signals low stress (high stress). We choose the threshold as the average over the all year of the sum of negative (positive) words.

In order to decide in which months the signal from the Monthly Bulletins is positive (no-stress) or negative (stress), we look at the weighted average of each month, as reported at the bottom of the table. If the monthly average for negative (positive) words is larger than the threshold negative (positive) in table 2 then the signal is negative. This will translate in a binary variable to take value $1(0)$. There will be cases in which the signal is not clear-cut, as, for example, the month of April 2007 in table 2. In particular, there will be cases in which both positive and negative signals are detected and cases where neither appear. In those cases we apply the following simple rule: if the monthly "average negative" minus one is larger than the monthly "average positive" then the signal will be coded as negative (i.e., one). In addition, we also look at the previous and subsequent period, as good and bad periods tend to cluster, the direction of the signal is usually confirmed by the signal of closest periods.

\footnotetext{
${ }^{9}$ Some sentences would be especially problematic, such as: "The enormous risks hitherto present in the economy have now completely disappeared and everything is fine." Luckily for our purposes, such phrases are unusual in the ECB Monthly Bulletins.

${ }^{10}$ Monthly Bulletins have become progressively lengthier. Results are robust also to other threshold measures, such as the simple sum (divided by the number of pages).
} 
Applying these rules is mostly but not completely straightforward; in the few ambiguous cases, we have applied judgment, also based on information from other sources. ${ }^{11}$

Table 2. Word-search: list of words and results for the year 2007

\begin{tabular}{|c|c|c|c|c|c|c|c|c|c|c|c|c|}
\hline & jan- 07 & feb-07 & mar-07 & apr-07 & maj-07 & jun-07 & jul-07 & aug-07 & sep-07 & okt- 07 & nov- 07 & dec- -07 \\
\hline slow* & 9 & 19 & 29 & 22 & 25 & 16 & 33 & 21 & 29 & 36 & 34 & 28 \\
\hline uncertain* & 20 & 36 & 26 & 41 & 25 & 21 & 31 & 19 & 41 & 26 & 46 & 44 \\
\hline weak* & 30 & 14 & 11 & 10 & 12 & 8 & 10 & 16 & 11 & 26 & 13 & 26 \\
\hline decelerat* & 4 & 7 & 2 & 6 & 3 & 5 & 8 & 5 & 5 & 9 & 7 & 1 \\
\hline adverse* & 2 & 3 & 2 & 2 & 0 & 0 & 8 & 8 & 4 & 1 & 11 & 5 \\
\hline risk* & 54 & 83 & 76 & 105 & 108 & 86 & 96 & 149 & 97 & 114 & 144 & 105 \\
\hline deteriorat* & 4 & 0 & 2 & 0 & 0 & 0 & 0 & 0 & 2 & 1 & 7 & 6 \\
\hline difficult* & 0 & 3 & 5 & 2 & 2 & 0 & 2 & 0 & 5 & 21 & 21 & 7 \\
\hline vigilant & 0 & 2 & 0 & 2 & 0 & 0 & 0 & 2 & 0 & 0 & 0 & 0 \\
\hline tension* & 4 & 0 & 0 & 3 & 0 & 4 & 4 & 6 & 21 & 43 & 36 & 45 \\
\hline imbalance* & 11 & 10 & 9 & 8 & 13 & 9 & 10 & 13 & 8 & 9 & 10 & 19 \\
\hline downturn & 0 & 0 & 2 & 2 & 0 & 3 & 2 & 0 & 1 & 1 & 2 & 2 \\
\hline contract* & 0 & 0 & 1 & 6 & 0 & 0 & 0 & 2 & 0 & 1 & 2 & 2 \\
\hline stabilis* & 9 & 5 & 8 & 2 & 5 & 6 & 10 & 10 & 7 & 4 & 7 & 6 \\
\hline improve* & 14 & 17 & 28 & 14 & 8 & 12 & 23 & 16 & 5 & 4 & 3 & 11 \\
\hline eas* & 7 & 22 & 8 & 2 & 28 & 5 & 2 & 30 & 8 & 24 & 5 & 11 \\
\hline expan* & 30 & 15 & 19 & 10 & 22 & 18 & 31 & 21 & 14 & 13 & 23 & 25 \\
\hline sound & 4 & 2 & 5 & 2 & 3 & 1 & 2 & 3 & 4 & 3 & 8 & 19 \\
\hline robust & 55 & 54 & 40 & 48 & 48 & 44 & 42 & 35 & 22 & 26 & 26 & 28 \\
\hline favourable & 23 & 25 & 46 & 33 & 28 & 43 & 33 & 35 & 33 & 17 & 20 & 21 \\
\hline recover* & 11 & 2 & 4 & 0 & 0 & 2 & 2 & 8 & 4 & 0 & 2 & 2 \\
\hline upturn & 4 & 0 & 0 & 5 & 2 & 2 & 6 & 3 & 0 & 1 & 0 & 0 \\
\hline turmoil & 0 & 0 & 8 & 11 & 0 & 8 & 4 & 17 & 20 & 13 & 51 & 39 \\
\hline crisis & 0 & 3 & 0 & 0 & 0 & 0 & 0 & 0 & 1 & 1 & 2 & 4 \\
\hline optimis* & 2 & 2 & 4 & 0 & 3 & 2 & 6 & 3 & 0 & 1 & 2 & 1 \\
\hline pessimis* & 0 & 0 & 0 & 0 & 0 & 0 & 0 & 0 & 0 & 1 & 0 & 1 \\
\hline average negative 2007 & 10 & 13 & 13 & 16 & 13 & 11 & 15 & 18 & 18 & 22 & 28 & 24 \\
\hline average positive 2007 & 16 & 14 & 16 & 12 & 15 & 14 & 16 & 17 & 10 & 10 & 10 & 12 \\
\hline threshold negative & 17 & & & & & & & & & & & \\
\hline threshold positive & 13 & & & & & & & & & & & \\
\hline
\end{tabular}

As can be seen from table 2, tensions were clearly higher in the markets from the summer 2007 till the end of the year. These are also the months where the average number of times the words of negative meaning are above the threshold whereas the words of positive meaning are below. For example, the words uncertainty and adverse tend to appear relatively often in the third and fourth quarter of 2007 and reach record high in November. Symmetrically, the words of positive meaning robust and favourable, reach the lowest levels in September and October.

Table 3 shows the results of the word search for the year 2000, i.e. the year when the dot.com bubble busted. As it appears in the table, the months from March to June are the

\footnotetext{
${ }^{11}$ Almost all data (or $90 \%$ of the observations) can be categorised in this automated way. For those observations that cannot, we have applied judgement based on information from other sources (see Appendix 2). Our preferred sources of information are The Economist and the Financial Times. This is not only for the high quality of such sources in terms of analysis and description of events but also because they are at a frequency that is suitable for our purposes.
} 
months where the frequency of negative words is higher. However, also the positive words score high and are above the threshold level for March and April and just equal to the threshold for the month of May.

Table 3. Word-search: list of words and results for the year 2000

\begin{tabular}{|c|c|c|c|c|c|c|c|c|c|c|c|c|}
\hline & jan-00 & feb-00 & mar-00 & apr-00 & maj-00 & jun-00 & jul-00 & aug-00 & sep-00 & okt-00 & nov- 00 & dec- 00 \\
\hline slow* & 57 & 25 & 29 & 66 & 18 & 42 & 24 & 25 & 41 & 4 & 43 & 98 \\
\hline uncertain* & 16 & 3 & 53 & 22 & 25 & 31 & 0 & 17 & 16 & 18 & 16 & 43 \\
\hline weak* & 14 & 20 & 13 & 24 & 14 & 8 & 11 & 14 & 14 & 11 & 9 & 17 \\
\hline decelerat* & 0 & 0 & 0 & 0 & 0 & 0 & 0 & 0 & 0 & 0 & 0 & 4 \\
\hline adverse* & 0 & 0 & 0 & 0 & 5 & 3 & 0 & 0 & 0 & 7 & 2 & 9 \\
\hline risk* & 30 & 18 & 40 & 24 & 41 & 63 & 18 & 22 & 30 & 16 & 14 & 28 \\
\hline deteriorat* & 0 & 0 & 0 & 0 & 0 & 0 & 0 & 0 & 0 & 0 & 0 & 0 \\
\hline difficult* & 0 & 0 & 3 & 2 & 0 & 7 & 0 & 0 & 0 & 0 & 2 & 1 \\
\hline vigilant & 3 & 0 & 2 & 2 & 2 & 0 & 0 & 0 & 0 & 0 & 0 & 0 \\
\hline tension* & 0 & 0 & 0 & 0 & 0 & 0 & 0 & 0 & 0 & 0 & 5 & 0 \\
\hline imbalance* & 0 & 0 & 2 & 0 & 5 & 2 & 0 & 0 & 0 & 0 & 2 & 5 \\
\hline downturn & 3 & 0 & 0 & 2 & 5 & 0 & 0 & 0 & 0 & 0 & 0 & 0 \\
\hline contract* & 0 & 0 & 3 & 0 & 0 & 0 & 0 & 0 & 1 & 0 & 5 & 1 \\
\hline stabilis* & 0 & 3 & 2 & 2 & 0 & 3 & 5 & 3 & 6 & 11 & 2 & 5 \\
\hline improve* & 14 & 8 & 11 & 15 & 9 & 12 & 24 & 14 & 12 & 4 & 9 & 4 \\
\hline eas* & 0 & 0 & 0 & 2 & 0 & 0 & 0 & 3 & 0 & 0 & 0 & 1 \\
\hline expan* & 16 & 23 & 10 & 17 & 7 & 24 & 3 & 14 & 10 & 4 & 7 & 21 \\
\hline sound & 0 & 0 & 2 & 0 & 0 & 5 & 5 & 0 & 0 & 2 & 2 & 1 \\
\hline robust & 8 & 15 & 3 & 5 & 9 & 12 & 5 & 14 & 13 & 11 & 5 & 10 \\
\hline favourable & 0 & 15 & 10 & 12 & 0 & 10 & 5 & 14 & 26 & 7 & 11 & 11 \\
\hline recover* & 32 & 20 & 16 & 12 & 2 & 20 & 11 & 17 & 14 & 0 & 2 & 7 \\
\hline upturn & 16 & 5 & 6 & 0 & 7 & 3 & 5 & 0 & 4 & 2 & 0 & 0 \\
\hline turmoil & 0 & 0 & 0 & 0 & 0 & 0 & 0 & 0 & 0 & 0 & 0 & 1 \\
\hline crisis & 0 & 0 & 2 & 0 & 0 & 0 & 0 & 0 & 0 & 2 & 2 & 0 \\
\hline optimis* & 11 & 3 & 11 & 0 & 0 & 3 & 5 & 0 & 6 & 2 & 0 & 0 \\
\hline pessimis* & 0 & 0 & 0 & 0 & 0 & 0 & 0 & 0 & 0 & 0 & 0 & $\underline{0}$ \\
\hline average negative 2000 & 12 & 7 & 15 & 14 & 11 & 16 & 5 & 8 & 10 & 6 & 10 & 20 \\
\hline average positive 2000 & 10 & 9 & 7 & 7 & 3 & 9 & 7 & 8 & 9 & 4 & 4 & 6 \\
\hline threshold negative & 11 & & & & & & & & & & & \\
\hline threshold positive & 7 & & & & & & & & & & & \\
\hline
\end{tabular}

These results are not surprising and are consistent with anecdotal evidence. Notably, the effects from the sharp decline in the NASDAQ composite index from its peak in March were beginning to be more widely felt on the European markets only from mid-spring. In fact, despite the sharp decline in the NASDAQ, the mood on the European markets remained fairly positive. For example, The Economist (2000a) referring to the dot.com focuses on the M\&As activities of several European stock exchanges. The editorial of the March Monthly Bulletin in 2000 (last paragraph on page 6) reports that:

"In conclusion, economic conditions and prospects for the euro area appear to be better at present than at any time in the past decade. Growth is strong, employment is expected to increase further and the still high level of unemployment should continue to fall. Remaining vigilant to counter upside risks to price stability and pursuing structural reform are the foundation for a sustained period of strong economic expansion and a lasting process of job creation."

In April after stating that there were risks to price stability, the editorial of the Monthly Bulletin (page 5) reports that: 
"...both consumer and industrial confidence have now reached levels which are at or close to the highest since the start of these series in the mid-1980s. This picture of continuing strong domestic demand supports the favourable outlook for economic growth in the euro area as shown in recent forecasts."

But even after the Black Friday (14th April) when the NASDAQ had lost 34\% compared only to one month earlier, in accounts from the financial press ..."most bulls remained ...bullish" (The Economist (2000b)) - even though market uncertainty was increasing with great speed.

Such patterns are also shown in the Chart 1 where in panel (a) are shown the words risk and uncertainty and in panel (b) the words robust and favourable. Chart 2 instead shows the weighted averages of negative and positive words for all the words in Tables 2 and 3.

Chart 1. Selected words frequency, year 2000 and 2007

Year 2007

(a)

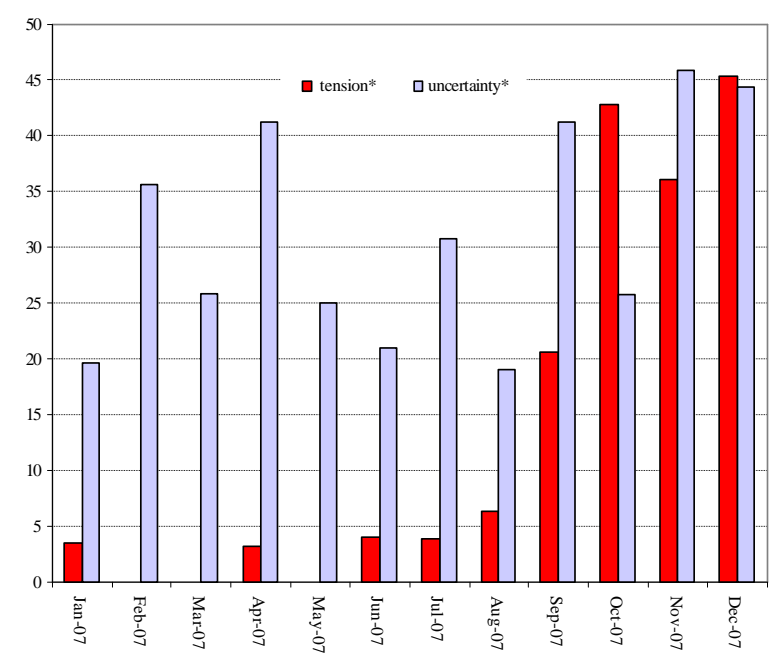

Year 2000

(a)

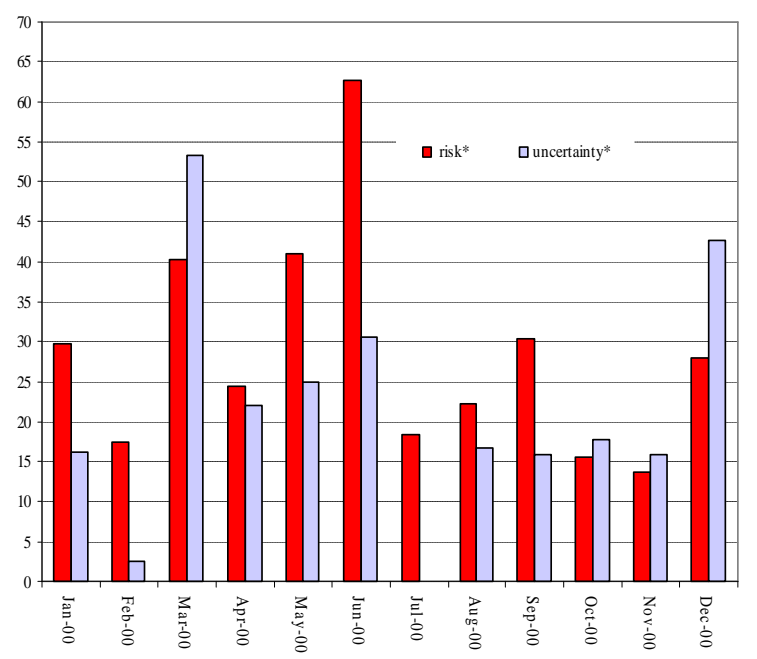


Year 2007

(b)

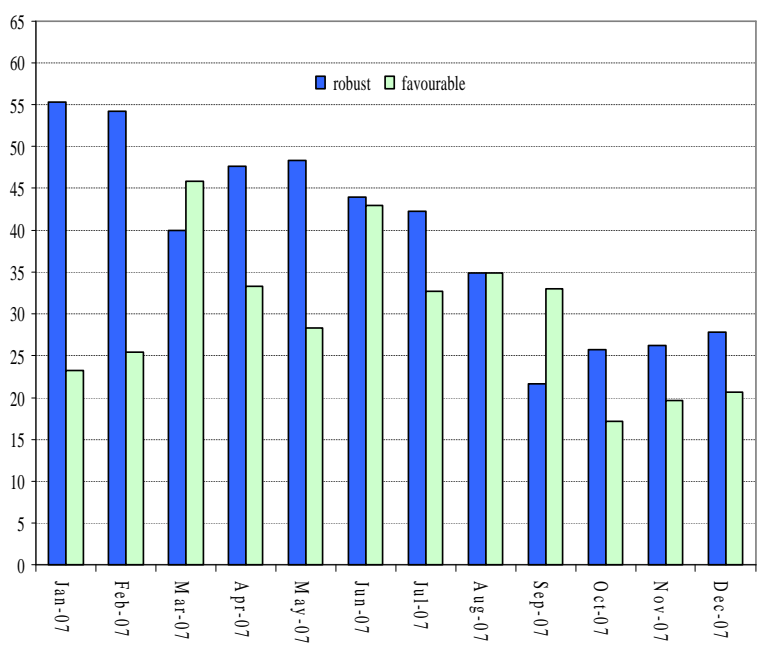

Year 2000

(b)

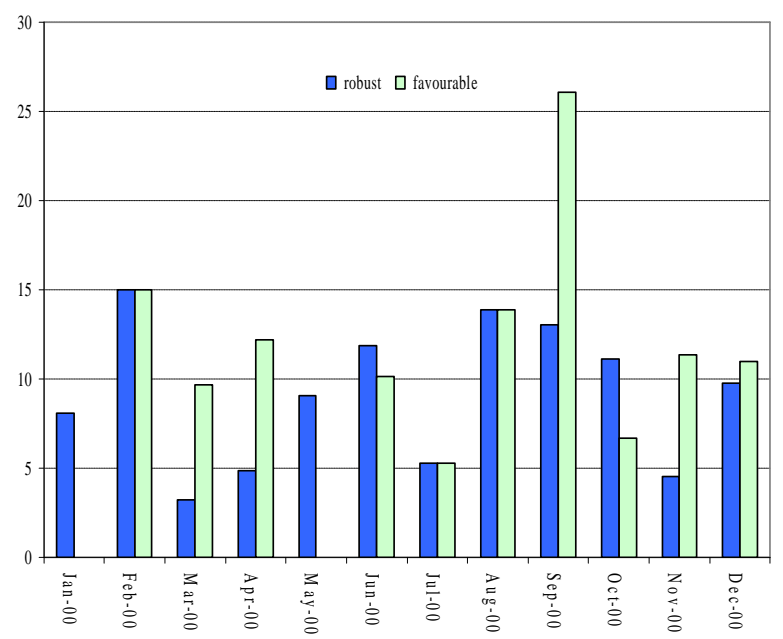

Chart 2. Average of negative and positive words, year 2007 and 2000

Year 2007

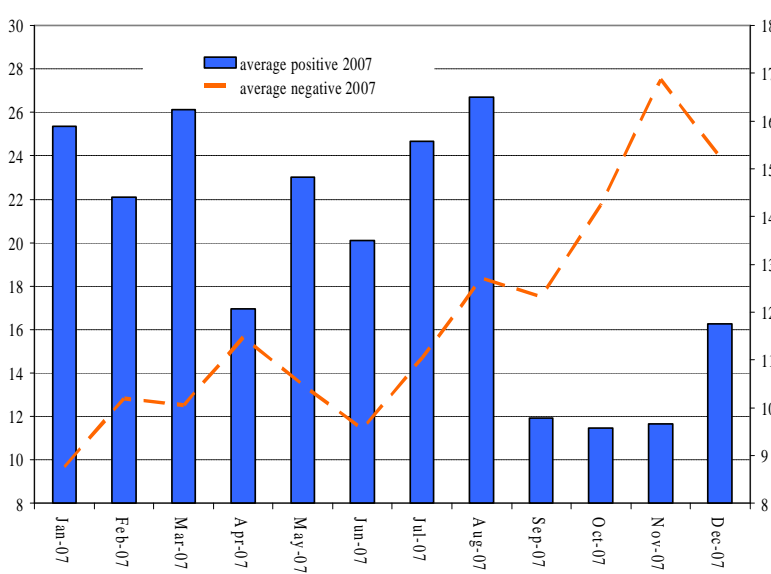

Year 2000

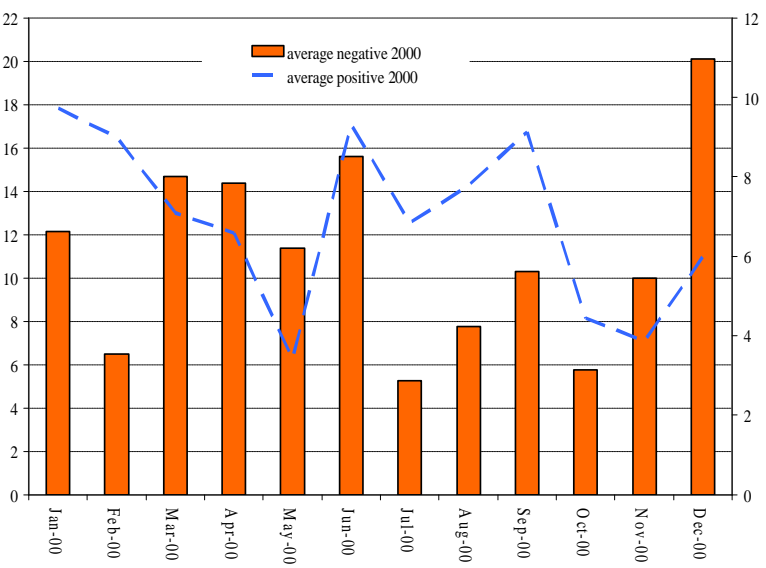

It is now uncontroversial that the crisis 2007-2009 was the most severe crisis in decades. Moreover, it was for the most part unexpected. Strikingly, this appears also from Chart 2 where on the left panel the average of positive and negative words for 2007 is represented. While the average for negative words was increasing since June 2007, the average of positive words sharply drops from September 2007 till the end of that year. It is also noteworthy that for the dot.com bubble, on the right panel of Chart 2, the average of negative words increases around the months of the bust and, correspondingly, that of the positive words declines but the overall picture is less clear-cut than in 2007.

To capture the information in our full sample, we repeated the word-search for each month of each year between July 1999 and October 2009. The results of this search are displayed in Table 4, where each word's appearance is simply aggregated over the respective 
year. As threshold value, we choose the average number of appearances for each word. At the bottom of the table, the last two rows show the average of the number of negative (stress) and positive (no-stress) words over the whole year. In Chart 3, we plot these two rows. Clearly, there are years in which stress was high and years (between 2004 and 2007) where it was low. As per construction, these years coincide with the years in which the average number of negative (positive) words as they appear in table 4 is above the threshold. Notably, for the years (2000-2003) when the average number of negative (positive) words is not above the threshold, the signal that there was stress in financial market is arguably weaker than at other points, notably in 2007, 2008 and 2009. ${ }^{12}$

Table 4. Word-search results, 1999 -2009

\begin{tabular}{|c|c|c|c|c|c|c|c|c|c|c|c|}
\hline & 1999 & 2000 & 2001 & 2002 & 2003 & 2004 & 2005 & 2006 & 2007 & 2008 & 2009 \\
\hline slow* & 50 & 39 & 75 & 35 & 17 & 23 & 36 & 29 & 25 & 62 & 40 \\
\hline uncertain* & 27 & 22 & 41 & 52 & 59 & 58 & 40 & 32 & 31 & 35 & 49 \\
\hline weak* & 16 & 14 & 36 & 30 & 38 & 21 & 33 & 18 & 15 & 49 & 53 \\
\hline decelerat* & 5 & 0 & 2 & 2 & 2 & 1 & 2 & 2 & 5 & 5 & 13 \\
\hline adverse* & 2 & 2 & 4 & 7 & 6 & 3 & 3 & 1 & 4 & 7 & 8 \\
\hline risk* & 33 & 29 & 37 & 29 & 38 & 54 & 73 & 91 & 102 & 98 & 56 \\
\hline deteriorat* & 0 & 0 & 6 & 2 & 2 & 2 & 2 & 1 & 2 & 9 & 11 \\
\hline difficult* & 1 & 1 & 5 & 10 & 8 & 3 & 3 & 2 & 6 & 0 & 0 \\
\hline vigilant & 1 & 1 & 0 & 1 & 0 & 1 & 0 & 0 & 0 & 0 & 0 \\
\hline tension* & 5 & 0 & 1 & 3 & 10 & 1 & 0 & 6 & 14 & 41 & 13 \\
\hline imbalance* & 1 & 1 & 4 & 8 & 7 & 9 & 7 & 12 & 11 & 8 & 4 \\
\hline downturn & 1 & 1 & 2 & 3 & 2 & 1 & 2 & 2 & 1 & 3 & 16 \\
\hline contract* & 3 & 1 & 1 & 1 & 1 & 2 & 1 & 1 & 1 & 5 & 26 \\
\hline stabilis* & 6 & 4 & 6 & 8 & 12 & 9 & 4 & 3 & 7 & 10 & 16 \\
\hline improve* & 19 & 11 & 3 & 9 & 13 & 21 & 20 & 18 & 13 & 5 & 9 \\
\hline eas* & 0 & 1 & 2 & 1 & 2 & 6 & 13 & 14 & 13 & 6 & 6 \\
\hline expan* & 9 & 13 & 5 & 6 & 5 & 12 & 8 & 14 & 20 & 15 & 8 \\
\hline sound & 0 & 1 & 3 & 4 & 3 & 5 & 4 & 5 & 5 & 8 & 3 \\
\hline robust & 5 & 9 & 6 & 3 & 4 & 21 & 30 & 38 & 39 & 19 & 5 \\
\hline favourable & 8 & 10 & 10 & 7 & 8 & 17 & 21 & 28 & 30 & 11 & 2 \\
\hline recover* & 18 & 13 & 8 & 25 & 19 & 35 & 10 & 9 & 3 & 3 & 9 \\
\hline upturn & 6 & 4 & 1 & 4 & 3 & 3 & 1 & 1 & 2 & 0 & 1 \\
\hline turmoil & 0 & 0 & 0 & 0 & 0 & 0 & 0 & 0 & 14 & 34 & 21 \\
\hline crisis & 2 & 1 & 1 & 1 & 1 & 0 & 2 & 0 & 1 & 4 & 12 \\
\hline optimis* & 0 & 3 & 1 & 3 & 4 & 4 & 2 & 1 & 2 & 1 & 0 \\
\hline pessimis* & 4 & 0 & 2 & 2 & 2 & 0 & 0 & 1 & 0 & 0 & 1 \\
\hline average negative & 14 & 10 & 16 & 13 & 15 & 14 & 16 & 15 & 17 & 28 & 25 \\
\hline average positive & 10 & 7 & 5 & 7 & 7 & 13 & 11 & 13 & 13 & 8 & 6 \\
\hline threshold negative & 17 & & & & & & & & & & \\
\hline threshold positive & 9 & & & & & & & & & & \\
\hline
\end{tabular}

\footnotetext{
${ }^{12}$ The year 1999 entries are based on monthly data from July to December. The year 2009 entries are based on monthly data from January to October.
} 
Chart 3. Stress (negative) and No-stress (positive) words, 1999- 2009, (yearly averages).

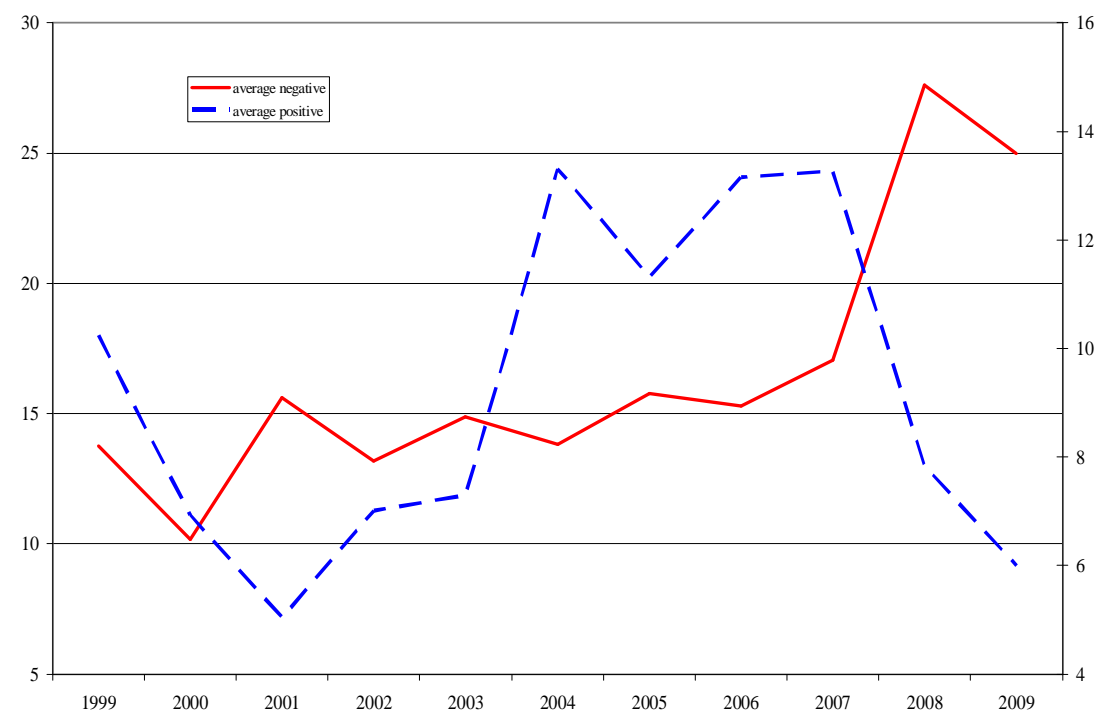

When comparing the results of the word-search with those based on the reading of the editorial and few selected sections of the Monthly Bulletins as well as of the financial press some differences emerge, as shown in Chart 4. However, given the different nature of the selection approaches and their different degree of subjectivity we would not expect the periods to overlap perfectly. For our purposes it suffices that periods so identified are in line with those identified with the more subjective approach based on the reading of the Monthly Bulletins and of selected financial press.

Chart 4. Periods of stress as identified through the MB approach and as in Table 1

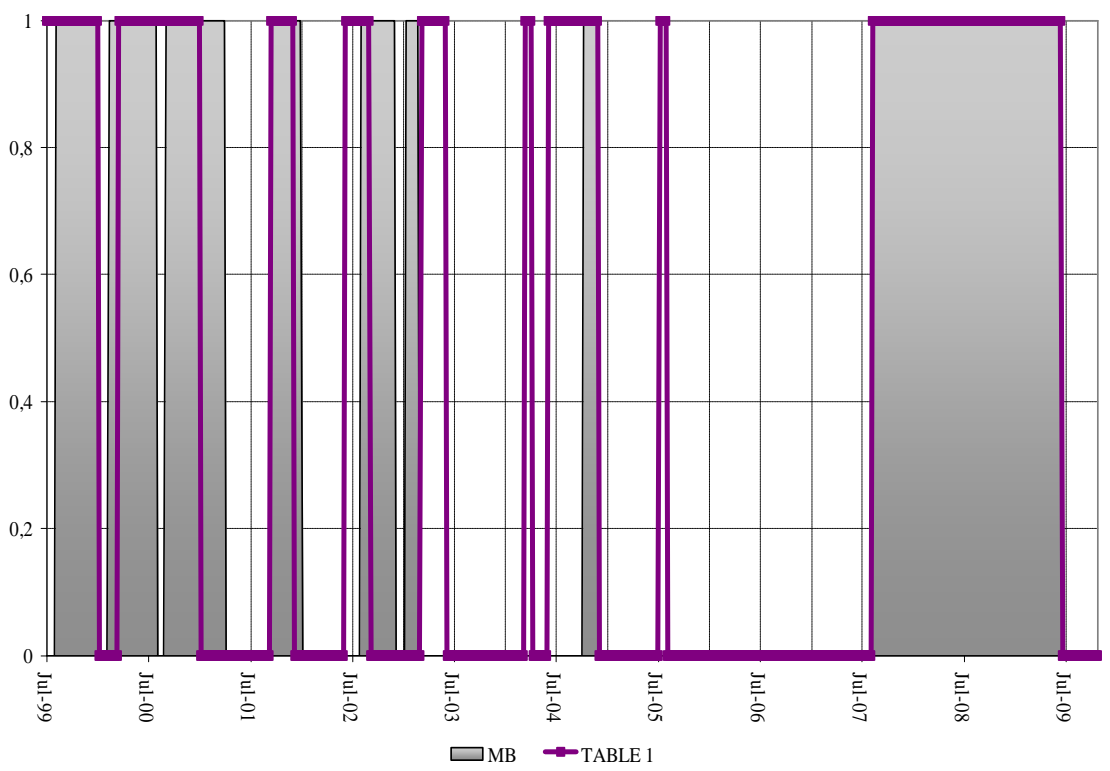

In Chart 4 we see that, while most of the periods of stress overlap, some periods are not signalled as stress according to the word-search, for example the period of the London 
bombings which caused disruptions and spread panic in July 2005 and the spring and summer of 2004 when oil prices spiked in the aftermath of the Iraq war and increasing geopolitical tensions. In section 3.4.2 we will look in details what these differences imply for the FSI.

\subsection{Selecting individual indicators}

In the previous section we have discussed the identification and dating of financial stress periods. In this section we describe the selection of the underlying variables which are at the core of our FSI.

We select 16 market-based individual variables as basic financial measures. In order to have data without too much noise, we choose only data that are of high quality, available at daily frequency, have economic relevance and are able to reflect agents' behaviour. Although this is somewhat restrictive and some information might be omitted, the underlying variables together cover a relatively broad spectrum of issues related to financial stress. Specifically, the variables reflect vulnerabilities in the corporate bond, government bond, banking, equity and money markets. We also included several measures that are commonly thought of as being a gauge of financial markets mood and to be a fairly reliable measure of agents' risk attitudes, such as the implied stock volatility. Vulnerability in the household sector is implicitly reflected in the behaviour of agents in these other markets. Table 5 below lists the variables grouped by market segment.

The choice of the variables reflects to some extent the choice of variables in related studies, including Kaminsky (1998) and Illing and Liu (2006). The corporate bond yield spreads are used as measures of stress for the corporate sector, see Illing and Liu (2006). They are computed as the difference in yield between the corporate bond and government bond indices with equivalent maturity. They can widen if expectations of future losses increase and/or uncertainty about their magnitude increases. In our sample we use corporate spreads related to three different rating classes, i.e. AA, BBB and High Yield.

For the sovereign bond markets we use the spreads between euro area countries long term bonds (10 years) vis-à-vis Germany long term (10 years) bond. ${ }^{13}$ In the literature, sovereign spreads are often related to fundamentals i.e. liquidity and credit risk premiums, as well as to market uncertainty. While liquidity and country creditworthiness usually play a

\footnotetext{
${ }^{13}$ The long term German bond, Bund, is commonly used as the benchmark , as it features both low liquidity and credit risk premiums.
} 
role, market uncertainty is commonly found to play a non trivial role, especially at times of stress when market uncertainty increases. ${ }^{14}$

For the banking sector, we use bank share prices to proxy for banking market stress. Similarly to the literature on stock market bubbles, an increase in bank share prices may be indicative of building-up of imbalances (bubble) and therefore might be interpreted as a signal of impending stress, while a sudden and protracted decrease in bank share prices (crash) is interpreted as a sign of stress. In addition, euro area major banks and financial institutions, which represent most of the financial institutions assets, fall in AA and A+ rating class. Therefore AA corporate bond spreads can be interpreted as a proxy of banking sector risk spread.

For the equity markets we use share prices, actual earnings per share and equity risk premium to proxy for stress. High equity risk premiums are (often) indicative of stress. A decline in earnings per share (EPS) may signify trouble and is often interpreted as a sign of stress.

We use the spreads between the Euribor and EONIA rates at different maturities as measures of liquidity-premium which may contain information about stress in the money markets. In addition, we include the spread between the main refinancing rate and the 2 year bond yield. This spreads is indicative of monetary liquidity with a downtrend suggesting a worsening of liquidity.

Finally, we use several measures of risk aversion like the implied stock volatility, which is computed through option prices and therefore contains information about expectations. We also include in our dataset several measures of uncertainty about the future level of interest rates, which may also reflect expectations about future monetary policy. An increase in such measures is interpreted as a sign of stress.

\footnotetext{
${ }^{14}$ In tranquil times, assuming that there are not (large) deviations from CIP, market uncertainty explains any statistically significant divergence in spreads.
} 
- AA risk spreads

- BBB risk spreads

- High-yield risk spread

- Sovereign bond spreads (Austria, Belgium, Finland, France, Greece, Ireland, Italy, Netherlands, Portugal, Spain versus Germany).

- DJ EUROSTOXX Financial
- Equity risk premium

- DJEuroSTOXX

- Actual earnings per share (EPS)

- $1 \mathrm{~m}$ Euribor-EONIA spread

- $3 \mathrm{~m}$ Euribor-EONIA spread

- Main refinancing rate $-2 \mathrm{yr}$ bond yield
- Long implied bond volatility

- Implied stock volatility

- Euribor futures implied volatility

- 1year forward 1 year swaption implied volatility (euro vs Euribor).

- 1 year forward 10 year swaption implied volatility (euro vs Euribor).

\subsection{Aggregating information from the underlying variables}

Following Nelson and Perli (2006), the information contained in these basic individual measures is summarised into two summary indices that capture their level and rate-of-change (Chart 5). Together these indices contain much of what characterises periods of stress that each one on their own might not detect. ${ }^{15}$

The first index, the level index, is a simple arithmetic average of the values of the individual variables, rescaled so that $1999=100$. The individual variables have been weighted by the inverse of their variances so that higher values of the index are associated with greater market stress. Chart 5 shows that from the relatively tranquil period from 2004 to the spring of 2007, the index dramatically increases from July 2007 onwards, reflecting the strains caused by the financial crisis $2007-2009$.

\footnotetext{
${ }^{15}$ Nelson and Perli (2006) include also a co-movement variable derived as the first component from a principal component analysis. We also included a similar variable but it was not significant and therefore we decided to drop it from the analysis.
} 
Chart 5. The level and the change indicators
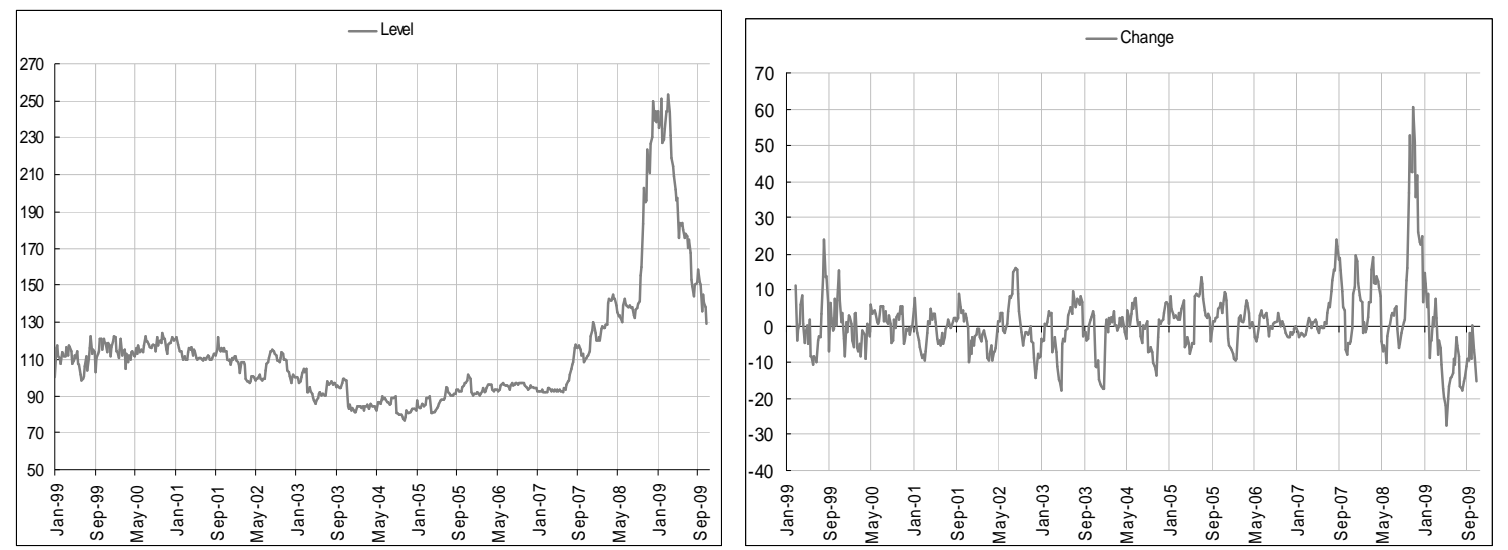

The speed with which the underlying market variables change may also give valuable information. For example, one would expect that when liquidity premiums, risk spreads and measures of uncertainty move higher, markets are becoming more vulnerable and stress is building up. Conversely when they move down rapidly, this might indicate that the period of (most) acute stress may be passed even if the index remains at elevated levels.

In order to capture this feature, we construct the second index, the rate-of-change. The right-hand panel of Chart 5 shows the rate-of-change of the level index computed over a rolling window (over 12 weeks). ${ }^{16}$

\subsection{Combining the underlying variables into a single indicator}

In the third step, the information contained in the two indices is combined into a single financial stress indicator obtained by using a logit-model to extract the information contained in the indices in an efficient way. Specifically, the index is constructed by including the two indices on the right-hand side and a binary variable (i.e., $S_{t}=0$ or 1 ) on the left-hand side of the regression. The binary variables $S_{t}$ identifies periods of financial stress, as we have identified in section $2.2:^{17}$

$$
\mathrm{S}_{\mathrm{t}+\mathrm{h}}=\mathrm{L}\left(\beta_{0}+\beta_{1} \lambda_{\mathrm{t}}+\beta_{2} \delta_{\mathrm{t}}\right) \quad \mathrm{h}>=0
$$

where $\lambda$ is the level index, $\delta$ the rate-of-change, $\beta_{\mathrm{i}}(\mathrm{i}=1,2)$ are the coefficients and L denotes the Logit probability distribution function. The model is estimated using weekly data from July 1999 to October 2009. The fitted probability from the estimation of equation 1 is the FSI.

\footnotetext{
${ }^{16}$ The length of the window is chosen as it has the highest R-squared in the logit model presented in section 2.5 . See also appendix 3 .

${ }^{17}$ We do not take explicitly into account dependence in the dependent variable. We use a robust HAC covariance matrix when we estimate the model (see Berg and Coke (2004)).
} 
Depending on the value of $h$, FSI is a contingent indicator $(h=0)$ or a forward indicator $(h>0)$. In the following section, we look at the FSI as a contingent indicator. In section 4, we will investigate the FSI properties as a forward (leading) indicator.

\section{The FSI: a contingent indicator}

When estimated with $\mathrm{h}=0$ the model in equation 1 is a model of a contingent indicator, i.e.

$$
S_{t}=L\left(\beta_{0}+\beta_{1} \lambda_{t}+\beta_{2} \delta_{t}\right)
$$

and therefore the FSI gives information about vulnerabilities and stress in the economy and their magnitude as they transpire.

\subsection{Insights from behavioural finance}

One criticisms of contingent stress indicators concerns how much value-added they provide over and above the data they draw on. While this contains an element of truth, such criticism is largely misplaced. In an environment where information is complex, interpreting the signals from a variety of sources is a challenge in its own right. The human brain has a limited capacity to acquire, process and use complex information. Because of such complexity and the limited capacity of the human brain, managing and using information is affected by behavioural aspects, and cognitive biases see Gilovich, Valone and Tversky (1985), Shleifer(2000), Barberis and Thaler (2004), De Grauwe and Grimaldi (2006). For example, it is now well-understood that economic agents tend to give a much larger weight to the last bit of information acquired, largely independent from the "true" relevance of it (Shrefin (2005)). Moreover, there is evidence that information is valued asymmetrically depending on the state of the markets, i.e. in a bull or bear market.

In volatile environments agents may tend to overreact and in so doing compound the complexity of the information and of the market itself. For one, in 2007 when the first elements of the financial crisis began to emerge, the mixture of strong and mild signals in an increasingly volatile environment made it difficult to understand where markets were heading and, in fact, that a period of acute stress was just around the corner. By the same token, once it is clear that the markets are in a 'crisis mode', understanding whether or not the bottom of the crisis has been reached is not a trivial exercise. Contingent indicators together with other information can function as the barometer in highly volatile markets and therefore they can be a useful tool in assessing the occurrence as well as the severity and the intensity of stress. 


\subsection{Computing the FSI}

Chart 6 shows the FSI, i.e. the fitted probability of being in a period of stress at each point in time as computed in equation 1 in the chosen sample period. The shaded areas represent the stressful periods as described in section 2. As can be seen from the chart, the indicator captures well-known periods of financial stress.

\section{Chart 6. Financial Stress Indicator and Periods of Financial Stress}

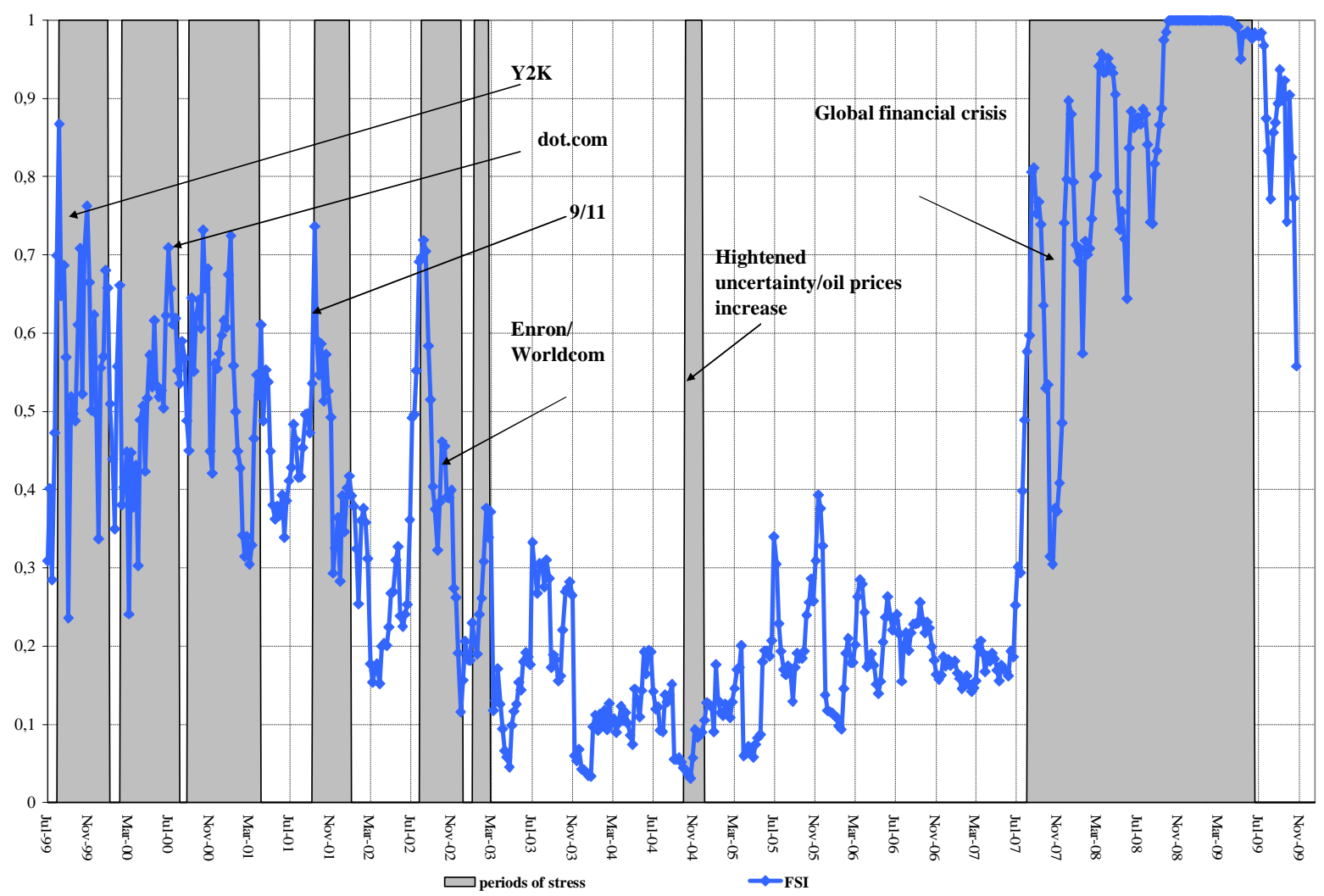

Not surprisingly, the period of August 2007 onwards emerges as the most acute episode of financial stress of recent history. Interestingly, the indicator captures also the switch in sentiment that the market experienced during the turmoil. For example, at times when major central banks temporarily succeeded in calming the markets by injections of liquidity the indicator decreases, only to increase again soon afterwards.

Notably, the indicator also shows an increase in the probability of stress at other, much less memorable, points in time. For example, there is a significant increase in 2000 in the wake of the dot.com bust. In 2002, financial markets experienced uneasiness originating 
from a string of defaults from large companies in telecommunications and was accompanied by the Worldcom implosion, the Enron and Vivendi-Universal accounting irregularities. ${ }^{18}$

\subsection{FSI compared to the VSTOXX and its noise/signal content}

In the previous section, we showed how the financial stress indicator could capture what, we now know, were instances of financial stress rather well and thus be in line with the anecdotal evidence. In this section, we instead ask how the indicator is systematically related to more general economic conditions. Though the indicator is able to measure and detect times of stress, it is useful to see this as measuring rod against other well-known indices of relatively high frequency.

In Chart 7 we show the FSI and the VSTOXX which represents the implied volatility of the Euro Stoxx 50 index. ${ }^{19}$ While the VSTOXX index is based on equity prices it is designed to reflect market's expectations of near-term volatility and, given its forwardlooking character, to be a more general measure of agents' perception of market uncertainty. The larger the value of the VSTOXX index the larger is market uncertainty. It is important to note that financial stress is related to - but is not - identical to market volatility. For example, there can be a lot of volatility in the market when new unexpected information arrives in a flow but this need not imply that there is stress in the market. On the opposite end, with high spreads signifying something amiss, for example that no trade is taking place, the volatility might be very low but stress very high. So while the VSTOXX measure is useful, these shortcomings imply that its role as an indicator is somewhat limited. Notably, the VSTOXX would have missed the onset of the financial crisis well into 2008.

\footnotetext{
${ }^{18}$ Among others, for example, the Adelphia, one of the largest US broadcasting companies, defaulted. In Europe $\mathrm{ABB}$, a Swedish Swiss engineering firm and Elan a biotech Irish firm were also caught in a string of severe accounting irregularities. See also Economist July $15^{\text {th }} 2002$.

${ }^{19}$ The VSTOXX Index is based on Dow Jones EURO STOXX 50 real time options prices.
} 


\section{Chart 7. The FSI and the VSTOXX index}

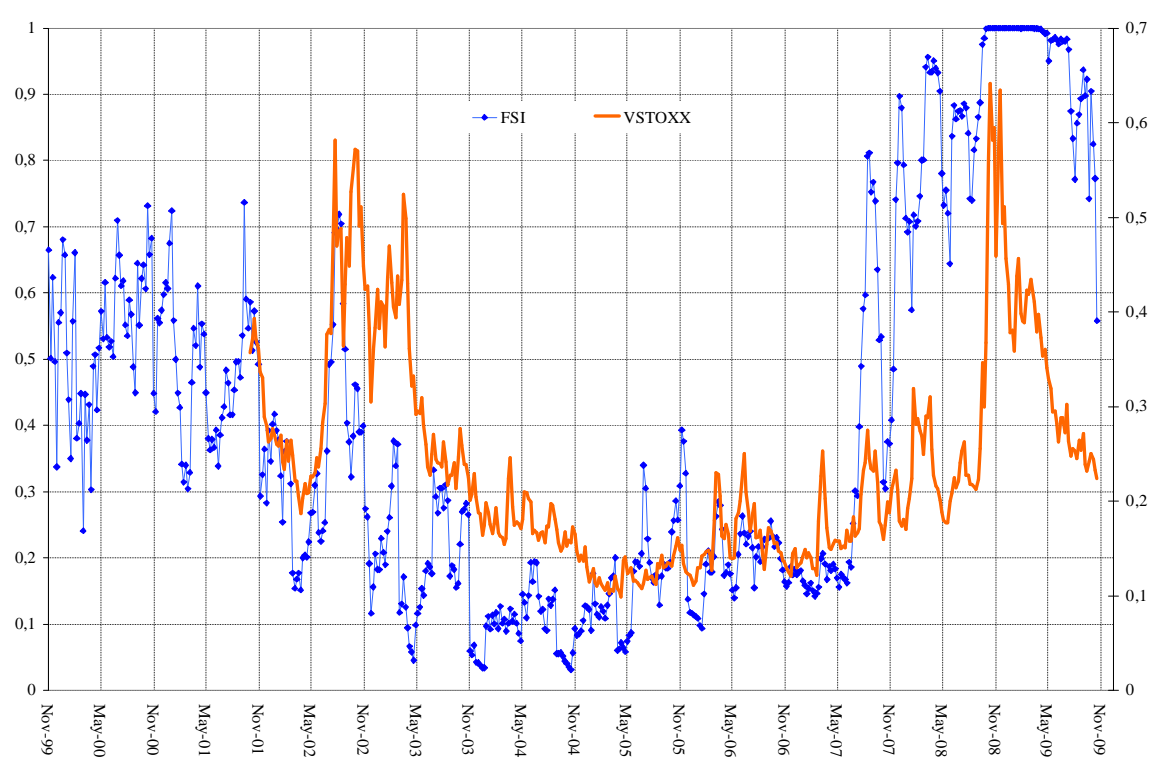

Another way to assess the signal/noise content of the FSI is to consider the number of false signals, positive or negative. One particularly simple way to do this is to consider a threshold level when the markets go from signalling a tranquil period to a period of stress. The critical threshold level is calculated so as to strike a balance between "bad" and "good" signals. A "bad" signal is a signal not followed by an actual period of stress within a certain horizon and a "good" signal is one followed by an actual period of stress within the chosen horizon, similar to Kaminsky, Lizondo, Reinhart (1998). We choose as horizon the current one week period, which is a useful starting point. Later in the analysis we will change the length of the horizon by varying the number of periods included.

There are four possible cases to consider. A first possible outcome is that a signal is followed by a stress period in the current one week period. A second possible outcome is that the signal is not followed by a stress period in the current one week period. A third one is that the signal has not been issued but a stress period occurs within the chosen window. The final possible outcome is that a signal was not issued and stress did not occur. Following Kaminsky, Lizondo, Reinhart (1999), this information can be summarised in the following matrix: 


\begin{tabular}{ccc}
\hline & Stress & No Stress \\
\hline Signal & A & B \\
No Signal & C & D \\
\hline
\end{tabular}

where $\mathrm{A}$ is the number of periods that a good signal was issued, B is the number of periods that a bad signal was issued, $\mathrm{C}$ the number of periods that a signal should have been issued (a missing signal) and $\mathrm{D}$ is the number of periods that a signal was, rightly, not issued. The ratio $\mathrm{C} /(\mathrm{A}+\mathrm{C})$ represents the share of missed periods of stress when stress occurred $(\mathrm{A}+\mathrm{C})$. It can also be interpreted as the share of type I errors. Similarly, the ratio $B /(B+D)$ represents the share of false alarms when stress did not occur $(\mathrm{B}+\mathrm{D})$ and therefore it also can be thought as the share of type II errors.

In addition, we impose another criterion on the persistence of the signal that requires a good signal to not only pass the threshold within the chosen window (i.e., the current one week) but also to stay above it for at least four weeks. In this way we reduce the cases where a right signal occurs as just a "blip". We choose to set the persistency window to the three periods before the current period, so that in total for a signal to be "good" the requirement is to pass the threshold for four consecutive weeks. In appendix 4, we show the results for different window lengths which also include forward periods.

Following Alessi and Detken (2009), the critical threshold is calculated so as to optimise a loss function of an agent, a policy maker for example, that takes into account her relative preferences regarding error type I and error type II. The loss function is defined as:

$$
\text { Loss }=\theta(\mathrm{C} /(\mathrm{A}+\mathrm{C}))+(1-\theta)(\mathrm{B}+/(\mathrm{B}+\mathrm{D}))
$$

The loss then can be interpreted as the preference weighted sum of type I and II errors. For value of $\theta$ lower than 0.5 the agent is increasingly less averse towards missing stress than to a false alarm. Correspondingly, for value of $\theta$ higher than 0.5 , the agent is more averse towards 
missing stress than towards receiving a false signal. Table 6 shows the loss function values associated with different thresholds when the agent has balanced preferences, i.e. $\theta=0.5{ }^{20}$

Table 6. FSI's Loss function values for different thresholds

\begin{tabular}{ccccccc} 
T & $\begin{array}{c}\text { False } \\
\text { Alarm }\end{array}$ & $\begin{array}{c}\text { Missing } \\
\text { Stress }\end{array}$ & $\begin{array}{c}\text { Right } \\
\text { Signal } \\
\text { Stress }\end{array}$ & $\begin{array}{c}\text { Right } \\
\text { Signal no- } \\
\text { stress }\end{array}$ & $\begin{array}{c}\text { Number } \\
\text { Obs }\end{array}$ & $\begin{array}{c}\text { LOSS } \\
\text { theta=0.5 }\end{array}$ \\
\hline \hline 0,1 & 274 & 8 & 216 & 37 & 535 & 0,46 \\
0,2 & 138 & 11 & 213 & 173 & 535 & 0,25 \\
$\mathbf{0 , 3}$ & 80 & 20 & 204 & 231 & 535 & $\mathbf{0 , 1 7}$ \\
0,4 & 48 & 46 & 178 & 263 & 535 & 0,18 \\
0,5 & 29 & 70 & 154 & 282 & 535 & 0,20 \\
0,6 & 19 & 105 & 119 & 292 & 535 & 0,26 \\
0,7 & 15 & 130 & 94 & 296 & 535 & 0,31 \\
0,8 & 13 & 157 & 67 & 298 & 535 & 0,37 \\
0,9 & 7 & 177 & 47 & 304 & 535 & 0,41 \\
\hline \hline
\end{tabular}

The first column shows the threshold values, while column 2 shows the number of weeks the FSI was above the threshold within a tranquil period (false signal). Column 3 shows the number of weeks the FSI was below the threshold within a stress period (missing signal). Column 4 and 5 show the right signal, when the FSI is above the threshold within a stress period and when it is below within a tranquil period respectively. The last column shows the Loss function value. The minimum value of the Loss function $(0.17)$ is associated with a threshold value 0.3 . Thus, we choose this as the critical threshold value.

At this critical threshold (0.3) Table 7 shows that overall the FSI signal is right most of the time and correctly picks out five episodes as risk for financial stress. While for some events like the dot.com bubble, the signal from the FSI is relatively strong, there are also periods in which there is more of a grey area. For example, for the period 2001Q3 the indicator signals market stress when stress did not occur (B for the matrix above, i.e. a false alarm). However, the evidence of financial markets developments was then particularly hard to interpret. In this period, a string of macroeconomic news highlighted an increased risk to the outlook for global growth and inflationary pressures with HIPC levels well above the $2 \%$ target thereby affecting market participants' perception about the strength of the economy. ${ }^{21}$

${ }^{20}$ Alessi and Detken (2009) argue that while values of $\theta$ 's lower than 0.5 may have been somewhat realistic prior to the global financial crisis (2007-2009), it is more likely in the wake of the crisis that preferences have shifted towards higher $\theta$. In Appendix 4 we show the values of the loss function for different $\theta$ 's at different threshold levels.

${ }^{21}$ This period was characterised by a general oil and price volatility. It was also the period of the outbreak of the mouth-and-foot disease. See ECB Monthly Bulletin April, May, June 2001 and Appendix 1 for a timeline of events. 
The period 2004Q4 is an example where the signal from the FSI is weak (missing signal, C for the matrix above). But again, the evidence is difficult to interpret. While this period was characterised by high levels and heightened volatility of oil prices, the outlook for the euro area remained fairly stable. ${ }^{22}$

Thus a few episodes that the FSI does not unequivocally pick out. It is in the nature of conflicting signals that no method may answer to all questions. But, as table 8 shows, the success ratio for the FSI is quite good and a considerable improvement over raw and noisy information from other sources. ${ }^{23}$

Table 7. FSIs' right and false signals

\begin{tabular}{|l|c|c|}
\hline Periods of financial stress & $\begin{array}{c}\text { Right signal } \\
\text { A }\end{array}$ & $\begin{array}{c}\text { False signal } \\
\text { B or C }\end{array}$ \\
\hline Y2K fear & $\odot$ & \\
\hline dot.com bubble & $\odot$ & \\
\hline Corporate accounting scandals & $\odot$ & \\
\hline 2001 Q3 & & $\bullet$ \\
\hline 9/11 & $\odot$ & \\
\hline Heightened uncertainty/inflationary pressures & & $\bullet$ \\
\hline Global financial crisis & $\odot$ & \\
\hline
\end{tabular}

${ }^{22}$ See Appendix 1 for a timeline of events.

${ }^{23}$ The success ratio is computed here as the number of right signals, respectively for $S=0$ and $S=1$, over the total number of observations, i.e. 535. This is a somewhat more conservative approach than the ratio computed as the number of right(false) signals over the total number of periods when a right(false) signal should have been issued. In Appendix 5 we report the success ratio for different threshold levels T computed with both approaches. 
Table 8. The FSI's Success Ratio

$\mathrm{T}=0.3 ; \theta=0.5$

\begin{tabular}{lcc}
\hline \hline & $\mathrm{S}=0$ & $\mathrm{~S}=1$ \\
\hline \% right signal & 43 & 38 \\
$\%$ false signal & 15 & 4 \\
\hline \hline
\end{tabular}

\subsection{Robustness properties}

\subsubsection{The FSI out-of-sample performance}

In this section we check the robustness of the FSI in one dimension by looking at its out-ofsample performance. In order to do this, we estimate the parameters of the FSI up to October 2006, i.e. well before the financial turmoil began in the summer 2007; consequently, these estimates use no information on the turmoil. We then estimate the FSI out-of-sample based on the estimated parameters. ${ }^{24}$ While it is desirable to compute an evaluation based on period-byperiod rolling regression type framework this is not entirely unproblematic in a Logit framework. Instead, we use a simple standard out-of-sample evaluation exercise as well as robustness tests in other dimensions of misspecification further below.

Chart 8 shows the resulting estimates in-sample, the blue continuous line, and out-ofsample, the dotted red line. The blue line is the FSI as estimated in the previous section and it can be thought as the "actual" FSI, while the red dotted line is the (out-of-sample) fitted FSI.

It can be seen that while the out-of-sample FSI is much less volatile than the "actual" FSI, it does pick the surge in stress around August 2007 and it remains at elevated levels during the all period of crisis. ${ }^{25}$ The performance of the FSI can be also measured by more formal tests such as the Root Mean Squared Error test reported in Table 9. The Root Mean Squared Error (RMSE), i.e. the root of sum of the squared differences between the out-of-

\footnotetext{
${ }^{24}$ We do not perform here a "true" forecast exercise but a conditional out-of-sample forecast based on the observed value for the out-of-sample period of the independent variables.

${ }^{25}$ The results are robust to different starting point of the out-of-sample period.
} 
sample estimates $(F X)$ and the in-sample values $(X)$ (forecast errors) divided by the number of periods in the out-of-sample period, can be written as:

$$
R M S E=\sqrt{\frac{\sum e_{t}^{2}}{h}}
$$

where $e_{t}^{2}$ are the squared forecast errors in period t, i.e. $e_{t}^{2}=(F X-X)^{2}$, h is the number of outof-sample periods. While the RMSE is one of the most common statistics used to evaluate forecast performance between different models it can be usefully applied also to evaluate the performance of the FSI - the lower the value the better the model fit. As can be seen from Table 9, its value is rather good at 0.38 . Further evidence of good performance is provided by Theil's inequality coefficient decomposition (Theil-U), which is based on RMSE but it scaled in such a way that it will always fall between 0 and 1 , just like a probability. ${ }^{26}$ It can be written as:

$$
\text { Theil }-U=\frac{\text { RMSE }}{\sqrt{\frac{\sum F X_{t}^{2}}{h}}+\sqrt{\frac{\sum X_{t}^{2}}{h}}}
$$

As a rule of thumb, a value of the Theil- $U<0.5$ indicates a good model fit, where Theil- $U=0$, i.e. when $\mathrm{FX}_{\mathrm{t}}=\mathrm{X}_{\mathrm{t}}$ for all $\mathrm{t}$, indicates that the model is a perfect fit and conversely if $\mathrm{U}=1$ then all other models would be better.

For ease of understanding, Theil's inequality coefficient can be usefully decomposed in three parts, usually labelled as the bias, the variance and the covariance. A robust model typically has a Theil- $\mathrm{U}<0.5$ but it would also be unbiased and have a small variance while leaving most of the difference between in-sample and out-of sample values to be attributable to the covariance (see Pyndyck and Rubinfeld (1991) and Brooks (2008)).

\footnotetext{
${ }^{26}$ RMSE for exchange rate models, for example, ranges between 0.6 and 0.8 (see Lam et al. (2008) for a summary table of forecasting performance of different models for major exchange rates. For GDP growth forecast see Hahn and Skudelny (2008) where RMSE ranges from relatively low ( less than 0.2) to very high (more than 0.8) depending on the sectors.
} 


\section{Chart 8. Out-of-sample estimation}

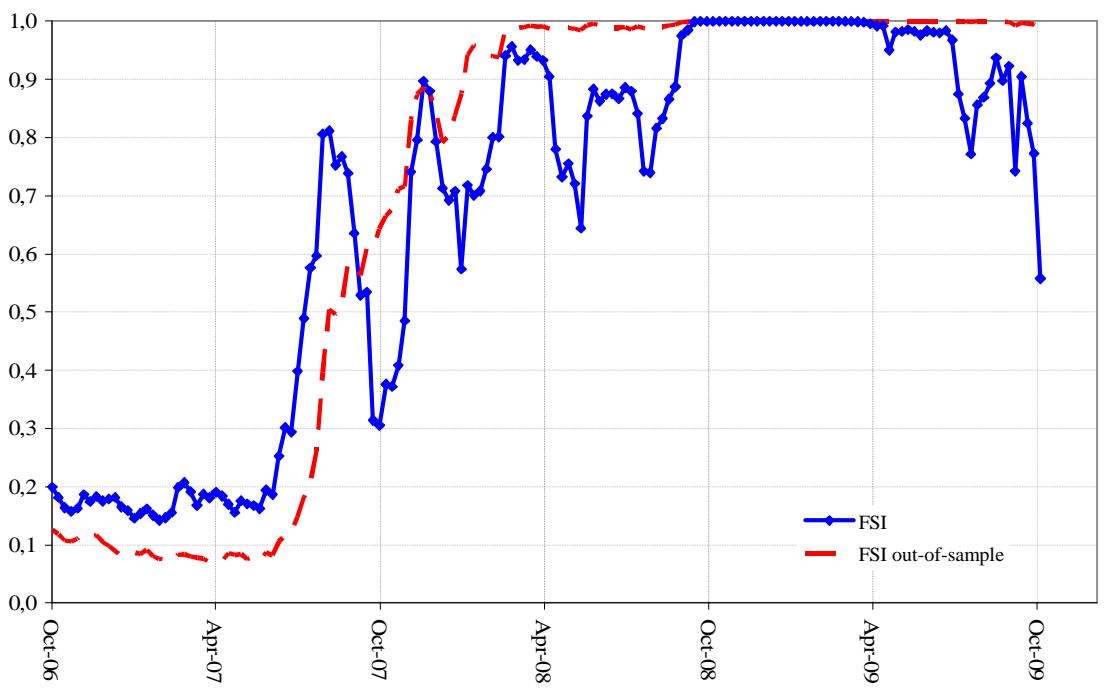

As shown in Table 9, the performance of the model is rather good as the bias and the variance proportions are relatively low ( 0.06 and 0.07 respectively) while the covariance proportion is high (0.88). Overall, the FSI performs relatively well.

Table 9. Evaluation of Fit

\begin{tabular}{|c|l|}
\hline Mean Squared Forecast Error & 0.38 \\
\hline Theil Inequality Coefficient & 0.24 \\
\hline Bias Proportion & 0.06 \\
\hline Variance Proportion & 0.07 \\
\hline Covariance Proportion & 0.88 \\
\hline
\end{tabular}

\subsubsection{The FSI with a mis-specified dependent variable}

One issue with indicators computed in a logit framework is that they may under some circumstances be sensitive to mis-specifications of the dependent variable. Therefore, it is particularly important to check the robustness of the FSI in this respect. To do this we create an ad-hoc dependent variable by introducing noise in our binary dependent variable of equation 1 . We introduce noise in the dependent variable by scrambling around a certain number of observations equal to $10 \%$ of the total number of observations (535). We then estimate the model as in equation 1 but with the ad-hoc dependent variable. Chart 9 shows the FSI as in the previous section and the FSI obtained with the new estimation based on the ad- 
hoc dependent variable. As Chart 9 shows, the new FSI based on the ad-hoc dependent variable closely mirrors the "true" FSI, i.e. the FSI as discussed in the previous sections.

Chart 9. The FSI and the FSI with 10\% noise

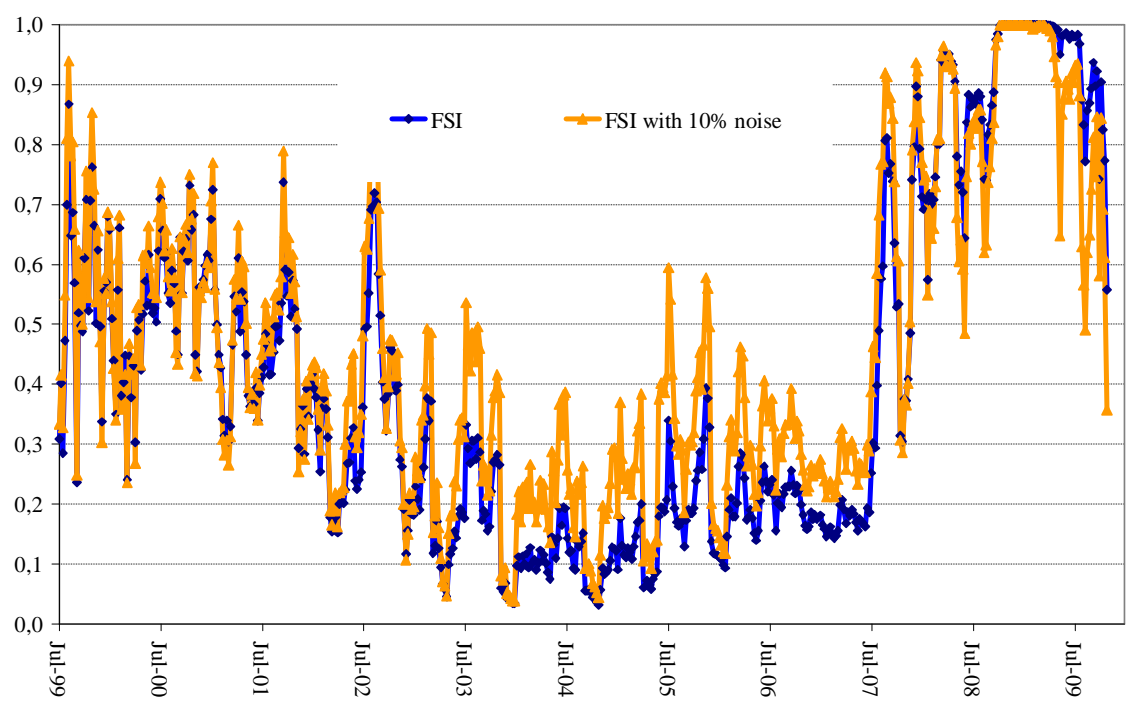

But what would then be the limit of the maximum noise to be introduced? We progressively introduced more and more noise in the dependent variable by scrambling around the observations in steps of 5\% of the total observations. We show the results in Chart 10.

\section{Chart 10. The FSI with different degrees of noise}

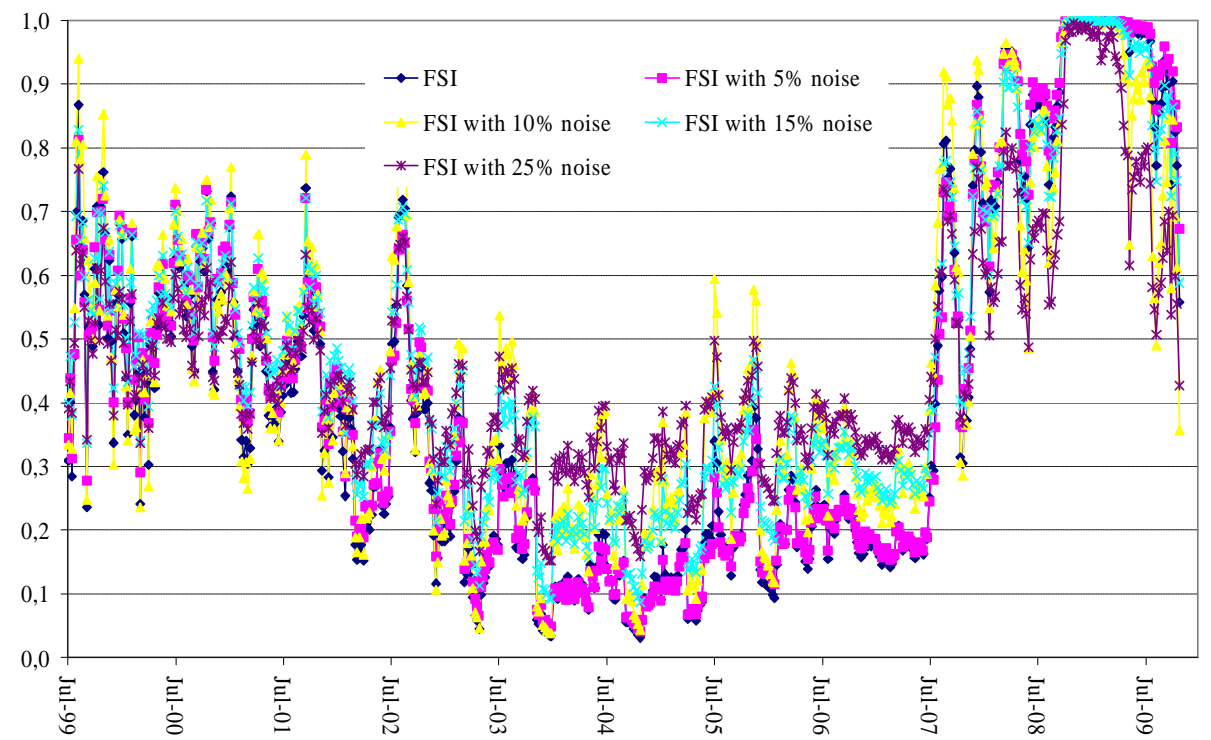

As can be seen from the chart, by increasing the noise of the dependent variable the accuracy of the FSI to correctly signal the periods of stress diminishes. It takes rather extreme amounts of scrambling (40\%) in order for signal of the FSI to become poor. Thus, for more plausible levels of distortion (say below 10\%), the results are robust and informative. 


\subsubsection{Comparing the FSI to one based only on anecdotal evidence}

In this section, we investigate how much value is added to the FSI constructed primarily from anecdotal evidence compared to an FSI that also includes the results of the word-search illustrated in section 2. Indeed, as a large part of our analysis is based on the fine tuning of the word search, it is desirable to know that the extra computation involved from the word-search yields better results.

In an ideal situation, relative statistical performance of the two different indicators of stress (FSI and FSI_anecdotal) could be mapped into a single measure to show the statistical gain, for example the classical $\mathrm{R}^{2}$-measure or values of the likelihood-function. Alas these methodologies are not readily applicable. Statistical techniques often rely on gains with respect to a specified endogenous variable (the " $y$ " in a typical regression framework), but in the paper we are computing two different endogenous variables and we do not know the "true" values. Indeed, in some sense, the "true" values of the endogenous variable are not interesting in their own right since they are mere constructions and can never be observed. The word-search adds value to the FSI if it contributes to detecting stress in a timely way without too many false positives. Thus, we compare the FSI with and without the word-search in several dimensions to be able to assess the total picture of how much performance is added by also including the word-search.

We proceed by constructing an indicator of stress (FSI_anecdotal) with the same methodology as for the FSI but based only on the evidence presented in Table 1. One way to compare the FSI and FSI_anecdotal is to assess the accuracy of the signal, i.e. the signal/noise ratios from the FSI and FSI_anecdotal. In table 10, we show the number of "bad" and "good" signals for FSI_anecdotal using the methodology from section 3 compared to FSI (in parenthesis, italics). Just as before, we choose the optimal threshold by minimising the Loss function in equation 3. By the Loss function measure, we can see that for all values of the threshold the FSI is a less noisy signal than the FSI-anecdotal. Although not strictly comparable, the optimum of the FSI based on a threshold of 0.3 has about $20 \%$ less noise or, alas, $20 \%$ more right signals than the FSI based only on anecdotal. ${ }^{27}$

\footnotetext{
${ }^{27}$ The FSI has $81 \%$ of right signal and $19 \%$ false signal; the FSI_anecdotal has $62 \%$ right signal and $38 \%$ false signal. See Appendix 5 for a detailed table.
} 
Table 10. FSI_anecdotal and FSI' s Loss function values for different thresholds

\begin{tabular}{|c|c|c|c|c|c|c|c|}
\hline & & & & & & SI_anecdotal & FSI \\
\hline $\mathbf{T}$ & $\begin{array}{c}\text { False } \\
\text { Alarm }\end{array}$ & $\begin{array}{c}\text { Missing } \\
\text { Stress }\end{array}$ & $\begin{array}{c}\text { Right } \\
\text { Signal } \\
\text { Stress }\end{array}$ & $\begin{array}{c}\text { Right } \\
\text { Signal no- } \\
\text { stress }\end{array}$ & $\begin{array}{c}\text { Number } \\
\text { Obs }\end{array}$ & $\begin{array}{c}\text { LOSS } \\
\text { theta }=0.5\end{array}$ & $\begin{array}{c}\text { LOSS } \\
\text { theta }=0.5\end{array}$ \\
\hline 0,1 & $292(274)$ & $6(8)$ & $232(216)$ & $5(37)$ & $535(535)$ & 0,50 & 0,46 \\
\hline 0,2 & $265(138)$ & $22(11)$ & $216(213)$ & $32(173)$ & $535(535)$ & 0,49 & 0,25 \\
\hline 0,3 & $156(80)$ & $47(20)$ & $191(204)$ & $141(231)$ & $535(535)$ & 0,36 & 0,17 \\
\hline 0,4 & $74(48)$ & $66(46)$ & $172(178)$ & $223(263)$ & $535(535)$ & 0,26 & 0,18 \\
\hline 0,5 & $29(29)$ & $85(70)$ & $153(154)$ & $268(282)$ & $535(535)$ & $\mathbf{0 , 2 3}$ & 0,20 \\
\hline 0,6 & $14(19)$ & $135(105)$ & $103(119)$ & $283(292)$ & $535(535)$ & 0,31 & 0,26 \\
\hline 0,7 & $7(15)$ & $161(130)$ & $77(94)$ & $290(296)$ & $535(535)$ & 0,35 & 0,31 \\
\hline 0,8 & $5(13)$ & 187 (157) & $51(67)$ & $292(298)$ & $535(535)$ & 0,40 & 0,37 \\
\hline 0,9 & $0(7)$ & $206(177)$ & $32(47)$ & $297(304)$ & $535(535)$ & 0,43 & 0,41 \\
\hline
\end{tabular}

Note: FSI values are reported in italics

One way to summarise these results is to compute the so called Relative Success Ratio:

$$
\text { Relative Success Ratio (right (false) signal) }=\frac{\text { FSI Success Ratio (right (false) signal) }}{\text { FSI_anecdotal Success Ratio (right (false) signal) }}
$$

In table 11 , we show the baseline case of $\mathrm{T}=0.3$ and $\theta=0.5$ while in appendix 5 we show the Relative Success Ratio for different threshold levels. The FSI has higher values in the case of right signals (164\% and 107\%) and lower values in the case of false signals (51\% and 43\%).

Table 11. Relative Success Ratio

\begin{tabular}{lcc}
$\mathrm{T}=0.3 ; \theta=0.5$ & & \\
\hline \hline & $\mathrm{S}=0$ & $\mathrm{~S}=1$ \\
\hline \% right signal & 164 & 107 \\
$\%$ false signal & 51 & 43 \\
\hline \hline
\end{tabular}

Note: the underlying success ratios are computed as in Table 8.

Finally, we also compute correlations between FSI and FSI_anecdotal (0.97) and S and S_anecdotal (0.63); the complete series for the FSI and FSI anectodal are shown below in Chart 11 together with arrows indicating significant events of stress based on anecdotal evidence. $^{28}$

\footnotetext{
${ }^{28}$ Chart 4 in Section 2.2 shows $\mathrm{S}$ and $\mathrm{S} \_$anecdotal.
} 
Chart 11. The FSI and FSI_anecdotal

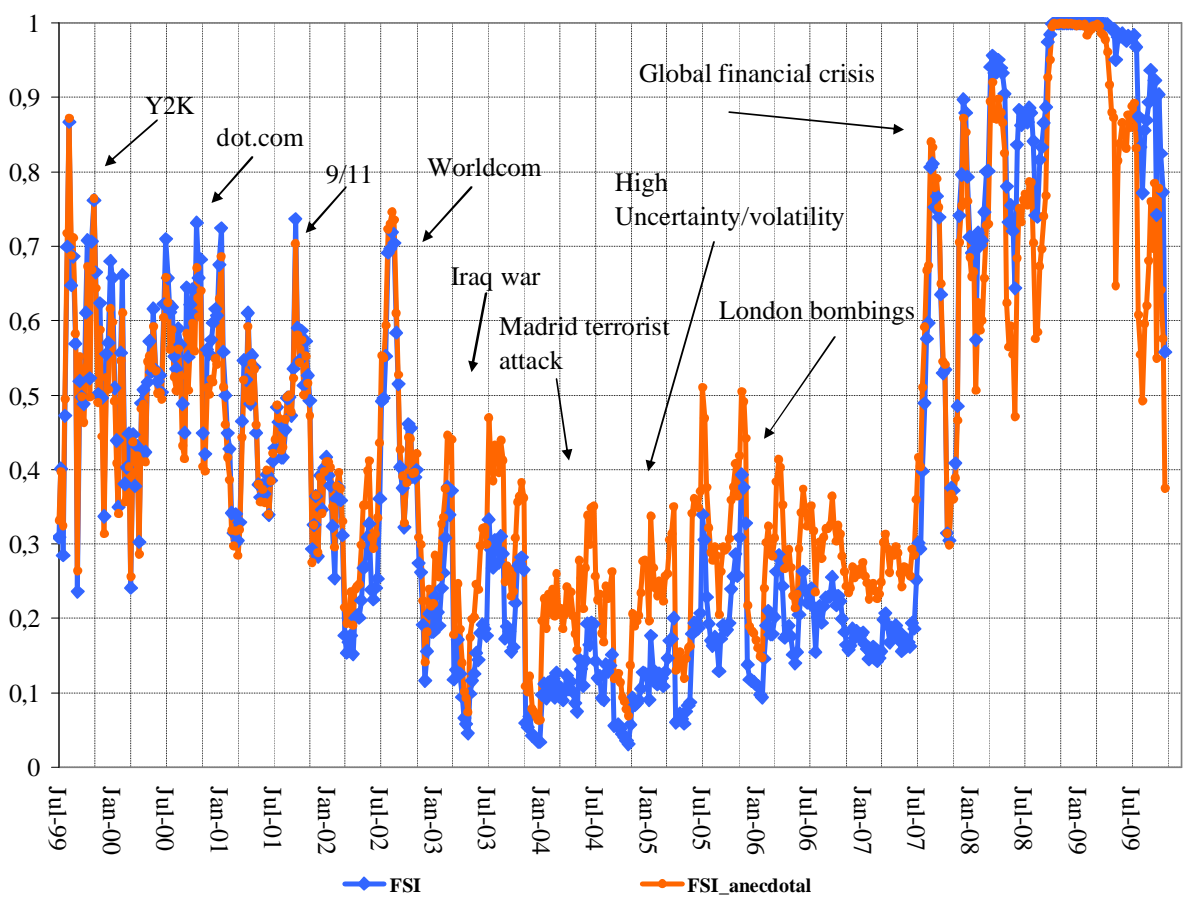

Overall, although we cannot readily devise a single number to show the enhanced performance of the FSI over the FSI_anecdotal, the results from several different indicators together indicate the word-search provides substantial value. One possible explanation for this result is that the blend of anecdotal evidence combined with a systematic word-search contains the best of both worlds.

\section{Predicting future stress - the FSI as leading indicator?}

Ideally, for each stress period one would like to know whether a stress indicator would capture the health of financial markets not only in a snapshot but also in the future and thus whether the indicator can be used as a leading indicator. Clearly, the property of leading indicator is particularly appealing as useful and timely information of future stress would enable policy makers as well as market participants to recognise vulnerabilities at an earlier stage and to take pre-emptive measures.

While the FSI is not originally constructed with the primary purpose of being an early-warning indicator, having such information might be useful. Thus, investigating to what extent the FSI contains properties of an early-warning indicator is interesting in its own right. 
While there are several ways to test the leading indicator properties of an index, it is not self-evident which one it is the best. One approach is to estimate the model in equation 1 with lagged independent variables. This means try to predict the exact timing of financial stress. But predicting the exact timing of future stress is very difficult, see for example Kaminsky (1998). Following Bussière (2007), Fuertes and Kalotychou (2004), Berg and Patillo (1999) we instead use another approach by making predictions on the occurrence of stress at any point in a time interval, for example over 24 weeks. More specifically, the second approach would extend the prediction window, by transforming the left-hand side variable of equation 1 as follows:

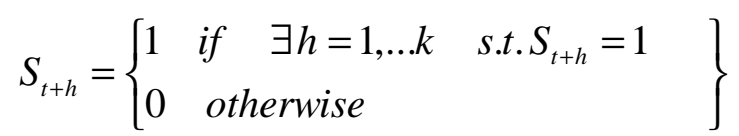

where $S_{t+h}$ is the forward binary variable and $\mathrm{k}$ is the length of the prediction window, in our example 24 weeks. But it leaves the right-hand side variables at time t, i.e.

$$
\mathrm{FFSI}_{\mathrm{t}}=\mathrm{L}\left(\beta_{0}+\beta_{1} \lambda_{\mathrm{t}}+\beta_{2} \delta_{\mathrm{t}}\right)
$$

Where, as in equation $1, \lambda$ is the level index, $\delta$ the rate-of-change, $\beta_{i}(i=1,2)$ are the coefficients and L denotes the Logit probability distribution function. FFSI is our forward FSI.

Chart 12 shows the FFSI when the prediction window is extended to 24 weeks, while in appendix 6 we show the FFSI with different forewarning horizon up to one year (54 weeks). ${ }^{29}$ The shaded areas in the chart are the stress periods as identified in the previous section 2.2. As the contingent FSI, the FFSI indicator increases during periods of stress while declining during tranquil periods. And again, the global financial crisis 2007-2009 appears to be the most severe episode of stress in our sample.

\footnotetext{
${ }^{29}$ We choose 24 periods (weeks) as this strikes a fair compromise between the desirable length of the period of forewarning for policy makers and the ability of the FFSI to reflect the state of the economy.
} 


\section{Chart 12. The FFSI and periods of stress}

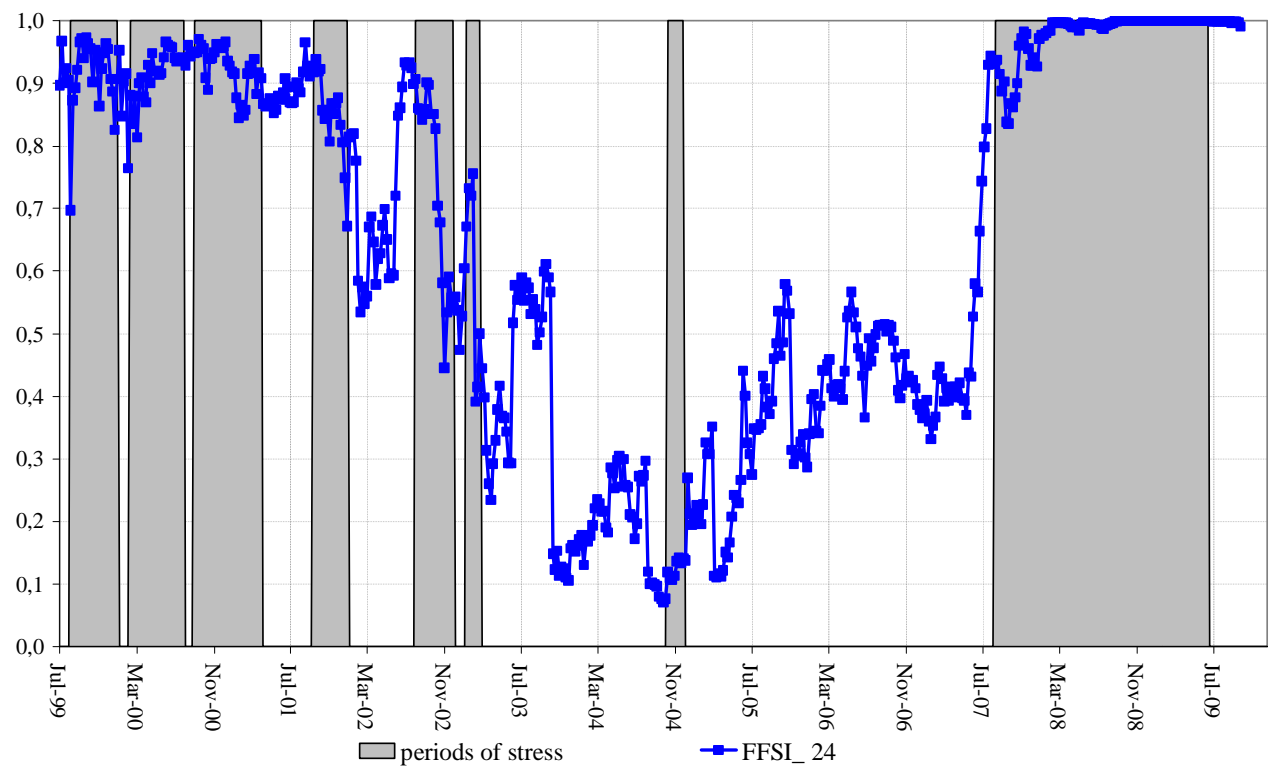

In order to measure the performance of the FFSI in terms of predicting future stress, it is useful to define a critical level i.e. a threshold, in the same spirit as in section 3.3. There are several ways to identify such a threshold, such as minimising a loss function (as we did for the FSI), by computing the noise-to-signal ratio, the historical mean level or moving averages.

To compute the threshold level T, we adopt a different approach for the FFSI. ${ }^{30}$ Following the insights from behavioural finance, we assume that the agent (or forecaster) gives a larger weight to the information from closer periods and a lower weight to the information further back in time, i.e. $\mathrm{T}$ is computed as a weighted average with declining exponential weights. ${ }^{31}$

We then assume that the forecaster has information up to time July 2007 and that it gives a larger weight, i.e. 0.5 , to the information collected in the previous period, i.e. one year. The forecaster then weights the information of the preceding years with increasingly lower weights, i.e. 0.25 for the information collected between July 2005 and July 2006, 0.12, for the information between July 2004 and July 2005, and so on. When computed under these assumptions the threshold level $\mathrm{T}$ is equal to 0.4 .

\footnotetext{
${ }^{30}$ The average of the FFSI is equal to 0.56; the minimum value for the Loss function is equal to 0.6. See Appendix 6.

${ }^{31}$ James (2006) reports that such behaviour is by large the most common among market participants when taking investment decisions based on future asset prices. See also Barberis and Thaler (2004) for a survey of behavioural finance.
} 
The level of the threshold $\mathrm{T}$ depends on the initial weight, as shown in Table 11. As we do not have a prior about which is the optimal weight, we chose the median (which is also the mode) of the threshold levels shown in table 12.

Table 12. Threshold and initial weights

\begin{tabular}{lccccccccr}
\multicolumn{10}{c}{ Initial weights } \\
\hline \hline & 0,1 & 0,2 & 0,3 & 0,4 & 0,5 & 0,6 & 0,7 & 0,8 & 0,9 \\
\hline \multirow{2}{*}{ Threshold } & 0,4 & 0,4 & 0,4 & 0,4 & 0,4 & 0,4 & 0,4 & 0,5 & 0,5 \\
& & & & & & & & & \\
\hline
\end{tabular}

While the FFSI does not cross the threshold and stays persistently above it, i.e. for at least four periods, before February 2006, it signals a shift in the level of stress by surging already from June 2005. It also displays a relatively large volatility around the threshold level for the period between June 2005 and May 2007. While this signal is not strong in absolute terms, it is remarkable when one considers that market participants at that time had continued to expect buoyant market conditions. It is also noteworthy that, once the turmoil started, it would have signalled that stress would be rising at a time when most of forecasters had failed to see the impending crisis.

\section{Conclusion}

By their very nature, rare events or so called "Black-Swans", pose special problems in modelling and for policymakers. While it may be reasonable to ignore extreme events when constructing models that are supposed to reflect "normal" times, we know that from time to time there will be moments of financial distress. Arguably this is an underdeveloped area of applied research and it is important to be able to detect and respond to them in a timely manner. Since many existing models did not help in predicting the financial crisis, there are good reasons for selecting methods that are more likely to pick up stress in real time than those based on conventional methods.

The FSI achieves this and has been shown to be a timely indicator. Although the model is not evaluated in a rolling-regression type framework, we show that the results are robust from a simple out-of-sample evaluation exercise as well as robust in various dimensions of misspecification. The FSI can be used both to assess the real time stance as well as to interact with models in a more formal way. One particularly important question is when the markets move beyond the more normal volatility and start to exhibit acute stress. The FSI can of course not answer this question unambiguously, but it provides a step in the 
right direction. Using appropriate threshold levels for the model, it is possible to more systematically identify when markets are in an acute period of stress. The FSI is shown to be rather robust and to be consistent with both anecdotal evidence and surpass other indices, such as VSTOXX, in terms of performance.

The FSI is not directly derived from theory or from an optimising model. This is both a strength and a weakness. The disadvantage of not being based on a model is that it is difficult to assess times when the measure may be prone to false signals. On the other hand, we have shown that the FSI is good in detecting financial stress and that the false positive signals are few. It would clearly be an advantage to have more formal models of rare events from mathematical finance. It is not the lack of such models that poses a problem, however, but how to implement them. Models with rare events are rather complicated and not entirely unproblematic to take to the data or to use in real time. Overall, therefore, the FSI may be a good compromise between ease of application and relevance. After all, we know that rare events occur from time to time and not being able to measure them at all, except after the fact, may not be entirely satisfactory. 


\section{Appendix 1. Timeline of events from July 1999 to October $2009^{32}$}

\section{July 1999-Dec 1999}

Financial markets are relatively volatile both within and outside the euro area, due in part to the perception by financial market participants of operational risks in connection with $\mathrm{Y} 2 \mathrm{~K}$. Financial market participants concerns start to decline from the second half of December 1999, after the successful completion of a series of year 2000 tests and an enhanced perception of a smooth transition to the year 2000.

\section{March 2000}

March 2000 was dominated by news about the bursting of the dot.com bubble. In 2000, the Nasdaq Composite index declined by close to $20 \%$ between end-February and mid-April. However, in the United States the positive outlook for future corporate earnings and the strength in the pace of economic activity continued (the Standard and Poor's 500 index recorded an increase by 7\%). In the euro area, broad indices of euro area stock prices declined in March mainly due to the correction in telecommunications and technology related stock prices and their strong growth of the previous months. However, both financial and energy sectors stock prices increased, partly compensating the decline.

\section{April 2000-December 2000}

Due to the spill-over effects from the bursting of the dot.com bubble to other sectors of the stock market, the volatility of stock prices, both within and outside the euro area, increased and remained high with an increased perception of an increasing deterioration of the broad economic outlook. Stock markets remained highly volatile for most of the year 2000 (In August 2000 volatility declined only to bounce back in September 2000). From the Monthly Bulletin in December 2000 (page 25):

"Continuing a pattern which has been evident for much of this year, conditions in the major stock markets were volatile in the course of November and early December. This mainly reflected heightened uncertainty on the part of market participants about the prospects for corporate profitability amid indications of a slowdown in the pace of global economic activity. ....Looking at the period since end-1999, stock prices in the euro area and the United States had declined by $3 \%$ and $7 \%$ respectively by 13 December. In Japan a decline of $19 \%$ took place over the same period."

\footnotetext{
32 Sources: ECB Monthly Bulletins, The Economist and Financial Times. A list of detailed and complete references is available upon request.
} 


\section{Jan 2001}

Long term yields declined substantially, being affected by increased uncertainty of market participants about future economic activity in US as well as in the euro area (though milder in the latter). Towards the end of January, this uncertainty started to ease. Stock markets were volatile in December and also started to ease in January while money market volatility was high during the all January.

\section{March 2001}

"...an element of uncertainty with regard to the outlook for euro area growth continues to be the world economy and its potential impact on euro area developments. However, at this juncture, there are no signs that the slowdown in the US economy is having significant and lasting spillover effects on the euro area.....Nevertheless, a close monitoring of global developments is warranted."

"As regards recent price developments, the annual rate of increase in the Harmonised Index of Consumer Prices (HICP) in January 2001, as published by Eurostat, was 2.4\%, having been $2.6 \%$ in the previous month. Oil prices and the euro exchange rate in January and February 2001 were subject to some volatility. Caution is therefore warranted in assessing their likely impact on HICP inflation in the short run. Moreover, indirect effects of past oil price increases and the depreciation of the euro are still coming through, as witnessed by the continued rise in producer price increases for consumer goods. Taken together, these factors might prevent consumer price inflation from falling below $2 \%$ for some months to come."

\section{April 2001}

"The deterioration in the external environment implies a somewhat stronger decline in economic growth in the euro area this year than was expected some months ago. Available forecasts suggest, however, that economic growth in 2001 will be in line with, or above, estimates of trend potential growth. Hence the moderation in growth should not be a source of pessimism as regards the economic strength of the euro area."

In the euro area, the Dow Jones EURO STOXX index fell by close to $9 \%$ between end-January and 28 February. Against the background of increasing uncertainty about global growth prospects during February, market participants appeared to revise their corporate 
earnings expectations downwards for euro area firms. This put downward pressure on stock prices, particularly in those sectors where revenues depend on the strength of external demand. In addition, stock prices in the euro area appeared to be subject to spill-over from global stock market developments in February.

\section{May 2001}

"Looking at the second pillar, available evidence indicates that upward risks to price stability over the medium term have diminished somewhat."

"First, owing to the less favourable external environment, a moderation in real GDP growth in the euro area will dampen upward pressure on prices. Recently released indicators of economic activity confirm this moderation. This notwithstanding, current forecasts indicate that economic growth, supported by domestic demand, will be broadly in line with estimates of trend potential growth in 2001."

"For some months to come, however, the medium-term inflation trend will be overshadowed by temporary developments in unprocessed food prices as a result of health concerns related to meat consumption and the consequences of foot-and-mouth disease. Moreover, the pass-through of the indirect effects of past rises in oil prices and the past depreciation of the euro is likely to continue for some months, as also suggested by recent data on producer prices."

\section{Sept 2001}

Financial market developments were dominated by the terrorist attacks in the United States on "9-11". In the euro area, the continued perception by market participants of a deteriorating outlook for economic growth was reinforced by the events in the United States, resulting in a substantial decrease of money market interest rates and bond yields (especially short-medium maturities) and a surge in volatility. However, towards the end of September and in early October, global financial markets stabilised somewhat and implied volatilities declined. 


\section{Oct 2001-early Nov 2001}

While the stock market recovered in October with a decrease of investors risk aversion, a string of macroeconomic data, such as confidence indicators, pointed towards a weak economic activity and resulting in substantial bond yields declines.

\section{Nov 2001}

In November there was a general recovery in financial markets. Led by the stock market recovery, bond yields reversed their declining trend and implied volatility in money markets decreased.

\section{June 2002-Aug 2002}

In the wake of the Enron-, Worldcom- and Vivaldi-U scandals, markets showed increasing stress, in part reflecting increasing concerns about the reliability of financial accounting information but also weaker than expected corporate earnings, bond yields as well as stock markets in the euro area and in the United States recorded sharp falls which reinforced the continued downward trend (see ECB Monthly Bulletin June 2002, page 28; The Economist $15^{\text {th }}$ Jul, Aug $1^{\text {st }}, 28^{\text {th }}$ Nov 2002).

\section{Sept 2002-Oct 2002}

After a short respite in September, geopolitical tensions and their possible impact on oil prices and stock market developments begin to materialise which results in a renewed increased uncertainty about the outlook for the global economy.

\section{Jan 2003-Mar 2003}

In the euro area amid a rise in uncertainty about the strength of the global recovery, increasing investors risk aversion and diminished consumer confidence due to the ongoing geopolitical tensions and the threat of further turbulence in the oil markets and lower employment, economic activity remained generally subdued.

The Iraq war was declared (See FT, 19 March 2003). 


\section{Mar-Apr 2004}

Mixed macroeconomic data releases as well as market participants' concerns about the impact of the appreciation of the euro on the international price competitiveness of euro area exporters contributed to the decline of bond yields and to an increase in short-term uncertainty which was compounded by the terrorist attacks in Madrid on 11 March. At the same time the economic outlook remained stable.

\section{Jun-Dec 2004}

In this period inflation goes up. Fears of shortages in the supply of oil increase. Oil prices are high and volatile (see The Economist, Jun $3^{\text {rd }}$, Jun $4^{\text {th }}$, Jun $10^{\text {th }}$, Aug $3^{\text {rd }}$, Aug $4^{\text {th }}$, Aug $5^{\text {th }}$, Aug $19^{\text {th }}$, Aug $20^{\text {th }}$, Sep $17^{\text {th }}$, Sep $23^{\text {rd }}$, Sep $30^{\text {th }}$, Oct $1^{\text {st }}$, Oct $21^{\text {st }}$, Oct $28^{\text {th }}$, Nov $4^{\text {th }}$, Nov $17^{\text {th }}$, Dec $2^{\text {nd }}$, Dec $\left.10^{\text {th }} 2004\right)$. At the same time, the outlook for the euro area remained fairly stable.

From the ECB Monthly Bulletin editorial September 2004: "The information which has become available in recent months indicates that the economic recovery in the euro area has maintained its momentum and should remain firm in the coming quarters. Inflation rates have been somewhat higher, mainly due to developments in oil prices". And again few months later: "The short-term outlook for inflation remains worrisome. At the current juncture oil price developments are having a sizeable impact on consumer prices in the euro area. However, there is no significant evidence that stronger underlying domestic inflationary pressures are building up" (ECB Monthly Bulletin editorial, December 2004).

\section{April 2005-June 2005}

A string of macroeconomic news, related to a slowdown of growth in major economies and developments in oil markets (the Brent crude oil reached the then historical high of USD 57, later to be double that amount) highlighted a somewhat increased risk to the outlook for global growth. At the same time, market participants' perception about the continued strength of the economy did not change substantially.

\section{July 2005}

7th July was the day of the deadly London bombings, followed just two weeks later (on the 22nd) by another (fortunately) failed attempt. In the wake of the terrorist attacks in London there was a rush for cover. For example, government bond prices across the globe increased 
due to flight-to-quality trades. However, the impact of the terrorist attacks did not have long lasting effects on financial markets. (See FT Jul 8th, Jul 9th, Jul 29th 2005).

\section{Oct 2005-Nov 2005}

The outlook for economic activity remains subject to downward risks, relating mainly to oil prices, concerns about global imbalances and weak consumer confidence. 


\section{Appendix 2: List of words and tables of "word-search"}

List of negative and positive words

\begin{tabular}{ll}
\hline \hline negative & positive \\
\hline slow* & stabilis* \\
uncertain* & improve* \\
weak* & eas* \\
decelerat* & expan* \\
adverse* & sound \\
risk* & robust \\
deteriorat* & favourable \\
difficult* & recover* \\
vigilant & upturn \\
tension* & optimis* \\
imbalance* & \\
downturn & \\
contract* & \\
turmoil & \\
crisis & \\
pessimis* & \\
\hline \hline
\end{tabular}




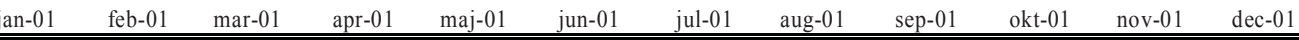

\begin{tabular}{|c|c|c|c|c|c|c|c|c|c|c|c|c|}
\hline slow* & 56 & 45 & 93 & 50 & 35 & 172 & 49 & 85 & 138 & 66 & 49 & 61 \\
\hline uncertain* & 44 & 7 & 43 & 25 & 17 & 67 & 7 & 75 & 27 & 43 & 60 & 80 \\
\hline weak* & 27 & 14 & 16 & 21 & 7 & 63 & 35 & 33 & 55 & 43 & 47 & 70 \\
\hline decelerat* & 0 & 0 & 4 & 0 & 0 & 16 & 0 & 0 & 0 & 0 & 0 & 3 \\
\hline adverse* & 0 & 5 & 1 & 2 & 2 & 2 & 14 & 4 & 5 & 2 & 4 & 6 \\
\hline risk* & 32 & 41 & 56 & 38 & 17 & 79 & 21 & 27 & 26 & 30 & 27 & 49 \\
\hline deteriorat* & 0 & 2 & 1 & 8 & 0 & 5 & 12 & 13 & 12 & 4 & 13 & 7 \\
\hline difficult* & 2 & 0 & 4 & 6 & 2 & 9 & 0 & 8 & 5 & 4 & 7 & 10 \\
\hline vigilant & 0 & 0 & 0 & 0 & 2 & 2 & 0 & 0 & 0 & 0 & 0 & 0 \\
\hline tension* & 0 & 0 & 0 & 0 & 0 & 0 & 0 & 0 & 0 & 9 & 0 & 2 \\
\hline imbalance* & 0 & 0 & 6 & 2 & 0 & 5 & 0 & 0 & 12 & 4 & 4 & 9 \\
\hline downturn & 0 & 0 & 1 & 0 & 0 & 5 & 0 & 2 & 7 & 2 & 4 & 3 \\
\hline contract* & 0 & 2 & 1 & 0 & 0 & 0 & 2 & 2 & 1 & 0 & 2 & 4 \\
\hline stabilis* & 2 & 7 & 4 & 0 & 9 & 16 & 9 & 0 & 7 & 2 & 2 & 11 \\
\hline improve* & 0 & 0 & 4 & 6 & 2 & 7 & 2 & 2 & 5 & 0 & 2 & 5 \\
\hline eas* & 0 & 0 & 0 & 2 & 0 & 2 & 2 & 4 & 5 & 0 & 2 & 7 \\
\hline expan* & 7 & 2 & 7 & 2 & 4 & 16 & 7 & 4 & 3 & 2 & 7 & 2 \\
\hline sound & 0 & 0 & 3 & 0 & 2 & 5 & 2 & 2 & 8 & 0 & 4 & 7 \\
\hline robust & 2 & 7 & 21 & 6 & 17 & 7 & 2 & 6 & 3 & 0 & 0 & 2 \\
\hline favourable & 2 & 0 & 18 & 6 & 4 & 28 & 9 & 10 & 14 & 9 & 9 & 11 \\
\hline recover* & 2 & 2 & 10 & 6 & 0 & 21 & 0 & 2 & 5 & 6 & 16 & 22 \\
\hline upturn & 0 & 0 & 0 & 0 & 7 & 0 & 0 & 0 & 0 & 0 & 0 & 2 \\
\hline turmoil & 0 & 0 & 0 & 2 & 0 & 0 & 0 & 0 & 1 & 2 & 0 & 0 \\
\hline crisis & 0 & 0 & 7 & 0 & 0 & 2 & 0 & 0 & 3 & 0 & 0 & 1 \\
\hline optimis* & 0 & 0 & 1 & 0 & 2 & 2 & 0 & 4 & 3 & 0 & 0 & 3 \\
\hline pessimis* & 0 & 5 & 1 & 6 & 7 & 2 & 0 & 0 & 3 & 4 & 0 & 1 \\
\hline average negative & 11 & 9 & 17 & 11 & 6 & 31 & 10 & 18 & 21 & 15 & 16 & 22 \\
\hline average positive & 2 & 2 & 8 & 3 & 5 & 12 & 4 & 4 & 6 & 2 & 5 & 8 \\
\hline threshold negative & 16 & & & & & & & & & & & \\
\hline threshold positive & 5 & & & & & & & & & & & \\
\hline
\end{tabular}

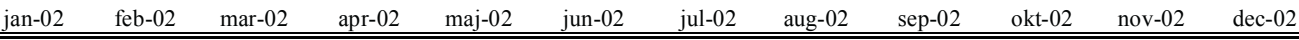

\begin{tabular}{|c|c|c|c|c|c|c|c|c|c|c|c|c|}
\hline & jan-02 & feb-02 & mar-02 & apr-02 & maj-02 & jun- 02 & jul-02 & aug-02 & sep-02 & okt- 02 & nov-02 & dec- 02 \\
\hline slow* & 31 & 34 & 55 & 35 & 33 & 77 & 13 & 13 & 40 & 31 & 18 & 36 \\
\hline uncertain* & 42 & 51 & 41 & 42 & 80 & 53 & 38 & 44 & 56 & 35 & 84 & 63 \\
\hline weak* & 38 & 34 & 43 & 23 & 14 & 50 & 24 & 13 & 51 & 18 & 20 & 36 \\
\hline decelerat* & 0 & 0 & 2 & 0 & 4 & 3 & 0 & 9 & 0 & 0 & 0 & 0 \\
\hline adverse* & 0 & 2 & 7 & 0 & 6 & 19 & 7 & 4 & 12 & 14 & 6 & 8 \\
\hline risk* & 42 & 13 & 34 & 23 & 24 & 26 & 20 & 31 & 29 & 55 & 20 & 33 \\
\hline deteriorat* & 4 & 0 & 3 & 2 & 2 & 2 & 0 & 0 & 1 & 2 & 0 & 2 \\
\hline difficult* & 8 & 17 & 13 & 5 & 6 & 10 & 4 & 4 & 12 & 20 & 14 & 6 \\
\hline vigilant & 2 & 0 & 0 & 0 & 2 & 2 & 2 & 0 & 0 & 0 & 0 & 0 \\
\hline tension* & 0 & 0 & 0 & 2 & 4 & 0 & 0 & 2 & 3 & 4 & 12 & 4 \\
\hline imbalance* & 4 & 0 & 14 & 2 & 8 & 16 & 7 & 9 & 12 & 10 & 2 & 9 \\
\hline downturn & 0 & 4 & 1 & 0 & 8 & 1 & 7 & 0 & 5 & 0 & 0 & 7 \\
\hline contract* & 0 & 0 & 3 & 0 & 0 & 1 & 0 & 0 & 4 & 2 & 2 & 1 \\
\hline stabilis* & 10 & 6 & 12 & 9 & 4 & 8 & 2 & 0 & 15 & 6 & 12 & 9 \\
\hline improve* & 6 & 11 & 8 & 16 & 4 & 14 & 4 & 4 & 13 & 8 & 6 & 14 \\
\hline eas* & 0 & 2 & 0 & 2 & 0 & 1 & 0 & 2 & 1 & 4 & 0 & 3 \\
\hline expan* & 2 & 4 & 2 & 2 & 4 & 3 & 13 & 11 & 8 & 10 & 10 & 5 \\
\hline sound & 0 & 4 & 5 & 2 & 4 & 3 & 2 & 0 & 6 & 6 & 6 & 5 \\
\hline robust & 0 & 0 & 1 & 0 & 4 & 10 & 0 & 0 & 8 & 2 & 0 & 5 \\
\hline favourable & 6 & 4 & 9 & 12 & 10 & 6 & 4 & 7 & 9 & 4 & 6 & 6 \\
\hline recover* & 17 & 17 & 30 & 28 & 22 & 45 & 20 & 18 & 44 & 12 & 8 & 35 \\
\hline upturn & 2 & 4 & 10 & 12 & 8 & 11 & 2 & 0 & 3 & 0 & 0 & 1 \\
\hline turmoil & 0 & 0 & 0 & 0 & 0 & 0 & 0 & 0 & 1 & 0 & 0 & 0 \\
\hline crisis & 0 & 4 & 1 & 0 & 0 & 0 & 0 & 0 & 3 & 0 & 0 & 0 \\
\hline optimis* & 0 & 6 & 9 & 5 & 4 & 2 & 0 & 0 & 1 & 4 & 6 & 2 \\
\hline pessimis* & 0 & 4 & 2 & 2 & 0 & 1 & 2 & 0 & 0 & 8 & 0 & 2 \\
\hline average negative & 12 & 12 & 16 & 10 & 14 & 19 & 9 & 9 & 16 & 14 & 13 & 15 \\
\hline average positive & 4 & 6 & 9 & 9 & 7 & 10 & 5 & 4 & 11 & 6 & 5 & 9 \\
\hline threshold negative & 13 & & & & & & & & & & & \\
\hline threshold positive & 7 & & & & & & & & & & & \\
\hline
\end{tabular}


$\begin{array}{lllllllllll}\text { jan-03 feb-03 } & \text { mar-03 } & \text { apr-03 } & \text { maj-03 } & \text { jun-03 } & \text { jul-03 } & \text { aug-03 } & \text { sep-03 } & \text { okt-03 } & \text { nov-03 } & \text { dec-03 }\end{array}$

\begin{tabular}{|c|c|c|c|c|c|c|c|c|c|c|c|c|}
\hline slow* & 14 & 2 & 37 & 21 & 5 & 27 & 27 & 12 & 24 & 4 & 18 & 18 \\
\hline uncertain* & 40 & 115 & 83 & 58 & 136 & 52 & 67 & 34 & 37 & 31 & 26 & 26 \\
\hline weak* & 28 & 33 & 74 & 33 & 31 & 48 & 35 & 54 & 37 & 27 & 26 & 28 \\
\hline decelerat* & 0 & 0 & 7 & 0 & 7 & 3 & 0 & 0 & 1 & 0 & 0 & 1 \\
\hline adverse* & 6 & 4 & 17 & 8 & 0 & 6 & 4 & 4 & 5 & 10 & 4 & 5 \\
\hline risk* & 22 & 26 & 20 & 15 & 166 & 40 & 31 & 26 & 29 & 22 & 30 & 33 \\
\hline deteriorat* & 0 & 9 & 0 & 2 & 0 & 4 & 2 & 4 & 0 & 0 & 2 & 4 \\
\hline difficult* & 8 & 4 & 14 & 8 & 24 & 5 & 12 & 4 & 3 & 6 & 2 & 7 \\
\hline vigilant & 0 & 0 & 0 & 0 & 0 & 0 & 0 & 0 & 0 & 0 & 0 & 0 \\
\hline tension* & 20 & 20 & 30 & 17 & 16 & 6 & 0 & 0 & 0 & 4 & 0 & 4 \\
\hline imbalance* & 6 & 4 & 10 & 0 & 3 & 22 & 6 & 4 & 13 & 6 & 5 & 6 \\
\hline downturn & 0 & 0 & 3 & 4 & 0 & 3 & 10 & 2 & 1 & 0 & 0 & 0 \\
\hline contract* & 0 & 0 & 0 & 0 & 3 & 1 & 2 & 2 & 0 & 2 & 4 & 2 \\
\hline stabilis* & 6 & 4 & 9 & 10 & 14 & 23 & 12 & 10 & 22 & 14 & 14 & 11 \\
\hline improve* & 16 & 7 & 4 & 4 & 5 & 14 & 22 & 10 & 20 & 12 & 25 & 20 \\
\hline eas* & 2 & 0 & 0 & 0 & 2 & 1 & 2 & 2 & 0 & 0 & 9 & 2 \\
\hline expan* & 2 & 4 & 4 & 4 & 10 & 5 & 2 & 4 & 6 & 8 & 4 & 7 \\
\hline sound & 2 & 2 & 2 & 4 & 3 & 11 & 0 & 0 & 5 & 0 & 2 & 8 \\
\hline robust & 2 & 0 & 5 & 2 & 3 & 6 & 0 & 2 & 12 & 2 & 4 & 8 \\
\hline favourable & 2 & 9 & 8 & 2 & 7 & 7 & 8 & 10 & 3 & 12 & 16 & 12 \\
\hline recover* & 8 & 20 & 20 & 4 & 9 & 22 & 31 & 18 & 27 & 20 & 16 & 31 \\
\hline upturn & 0 & 0 & 0 & 0 & 0 & 5 & 12 & 2 & 6 & 8 & 2 & 2 \\
\hline turmoil & 0 & 0 & 0 & 0 & 0 & 0 & 2 & 0 & 0 & 0 & 0 & 0 \\
\hline crisis & 0 & 0 & 0 & 0 & 2 & 3 & 2 & 0 & 1 & 0 & 2 & 6 \\
\hline optimis* & 2 & 2 & 2 & 0 & 0 & 1 & 6 & 8 & 8 & 4 & 5 & 5 \\
\hline pessimis* & 2 & 2 & 2 & 2 & 5 & 3 & 0 & 0 & 2 & 0 & 0 & 0 \\
\hline average negative & 11 & 17 & 23 & 13 & 31 & 17 & 15 & 11 & 12 & 9 & 9 & 11 \\
\hline average positive & 4 & 5 & 5 & 3 & 5 & 9 & 10 & 7 & 11 & 8 & 9 & 11 \\
\hline
\end{tabular}

15
7

threshold positive

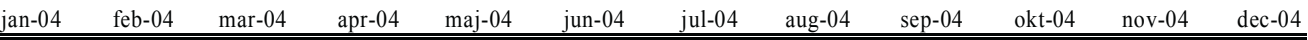

\begin{tabular}{|c|c|c|c|c|c|c|c|c|c|c|c|c|}
\hline slow* & 9 & 27 & 32 & 8 & 16 & 18 & 20 & 16 & 30 & 46 & 24 & 33 \\
\hline uncertain* & 55 & 52 & 46 & 92 & 69 & 42 & 52 & 58 & 47 & 57 & 57 & 69 \\
\hline weak* & 17 & 15 & 31 & 24 & 10 & 14 & 18 & 20 & 21 & 26 & 25 & 33 \\
\hline decelerat* & 0 & 0 & 0 & 0 & 0 & 0 & 0 & 0 & 10 & 2 & 0 & 6 \\
\hline adverse* & 6 & 0 & 7 & 4 & 2 & 4 & 0 & 0 & 2 & 0 & 4 & 9 \\
\hline risk* & 38 & 40 & 81 & 45 & 49 & 37 & 42 & 58 & 51 & 48 & 65 & 94 \\
\hline deteriorat* & 9 & 0 & 9 & 0 & 0 & 1 & 0 & 0 & 0 & 0 & 0 & 1 \\
\hline difficult* & 2 & 2 & 10 & 0 & 2 & 0 & 2 & 5 & 5 & 4 & 0 & 6 \\
\hline vigilant & 0 & 0 & 0 & 0 & 0 & 1 & 4 & 0 & 1 & 0 & 0 & 0 \\
\hline tension* & 0 & 0 & 3 & 0 & 0 & 0 & 0 & 0 & 2 & 0 & 4 & 0 \\
\hline imbalance* & 4 & 6 & 24 & 8 & 8 & 16 & 4 & 4 & 12 & 0 & 4 & 18 \\
\hline downturn & 0 & 2 & 7 & 0 & 0 & 1 & 2 & 0 & 4 & 0 & 0 & 0 \\
\hline contract* & 0 & 2 & 0 & 4 & 2 & 3 & 6 & 0 & 1 & 2 & 2 & 0 \\
\hline stabilis* & 13 & 6 & 15 & 4 & 4 & 13 & 10 & 4 & 17 & 4 & 10 & 9 \\
\hline improve* & 28 & 38 & 37 & 18 & 33 & 16 & 4 & 16 & 20 & 9 & 18 & 18 \\
\hline eas* & 0 & 2 & 7 & 0 & 0 & 1 & 0 & 31 & 4 & 2 & 25 & 0 \\
\hline expan* & 11 & 6 & 13 & 10 & 14 & 11 & 14 & 11 & 14 & 11 & 16 & 12 \\
\hline sound & 4 & 2 & 12 & 0 & 2 & 6 & 12 & 4 & 2 & 4 & 2 & 5 \\
\hline robust & 4 & 13 & 18 & 22 & 24 & 28 & 26 & 20 & 30 & 28 & 14 & 26 \\
\hline favourable & 19 & 13 & 21 & 20 & 16 & 19 & 8 & 15 & 16 & 20 & 14 & 21 \\
\hline recover* & 43 & 33 & 47 & 55 & 39 & 48 & 40 & 35 & 26 & 26 & 14 & 15 \\
\hline upturn & 4 & 4 & 4 & 6 & 6 & 0 & 2 & 9 & 0 & 2 & 0 & 2 \\
\hline turmoil & 0 & 0 & 0 & 0 & 0 & 0 & 0 & 0 & 0 & 0 & 2 & 0 \\
\hline crisis & 0 & 0 & 0 & 0 & 0 & 0 & 0 & 0 & 0 & 0 & 2 & 0 \\
\hline optimis* & 6 & 6 & 16 & 6 & 4 & 4 & 2 & 0 & 4 & 0 & 2 & 0 \\
\hline pessimis* & 0 & 0 & 0 & 0 & 0 & 0 & 2 & 0 & 0 & 0 & 0 & 0 \\
\hline average negative & 12 & 12 & 21 & 15 & 13 & 11 & 13 & 13 & 16 & 15 & 16 & 22 \\
\hline average positive & 13 & 12 & 19 & 14 & 14 & 15 & 12 & 14 & 13 & 11 & 11 & 11 \\
\hline threshold negative & 15 & & & & & & & & & & & \\
\hline threshold positive & 13 & & & & & & & & & & & \\
\hline
\end{tabular}


$\begin{array}{lllllllllll}\text { jan-05 feb-05 } & \text { mar-05 } & \text { apr-05 } & \text { maj-05 } & \text { jun-05 } & \text { jul-05 } & \text { aug-05 } & \text { sep-05 } & \text { okt-05 } & \text { nov-05 } & \text { dec-05 }\end{array}$

\begin{tabular}{|c|c|c|c|c|c|c|c|c|c|c|c|c|}
\hline slow* & 60 & 26 & 44 & 58 & 39 & 41 & 59 & 19 & 20 & 21 & 32 & 6 \\
\hline uncertain* & 68 & 91 & 24 & 13 & 28 & 26 & 36 & 26 & 30 & 40 & 54 & 43 \\
\hline weak* & 42 & 28 & 27 & 31 & 27 & 32 & 44 & 29 & 33 & 37 & 48 & 22 \\
\hline decelerat* & 2 & 4 & 0 & 6 & 9 & 5 & 0 & 0 & 2 & 0 & 0 & 2 \\
\hline adverse* & 6 & 4 & 6 & 0 & 0 & 7 & 2 & 3 & 5 & 2 & 5 & 3 \\
\hline risk* & 66 & 86 & 67 & 77 & 91 & 52 & 66 & 71 & 90 & 61 & 75 & 71 \\
\hline deteriorat* & 0 & 2 & 2 & 2 & 3 & 1 & 2 & 0 & 2 & 0 & 5 & 0 \\
\hline difficult* & 2 & 0 & 4 & 12 & 0 & 4 & 3 & 0 & 1 & 6 & 3 & 3 \\
\hline vigilant & 0 & 0 & 0 & 0 & 2 & 1 & 2 & 0 & 0 & 0 & 0 & 1 \\
\hline tension* & 0 & 0 & 0 & 0 & 0 & 2 & 0 & 0 & 0 & 0 & 0 & 2 \\
\hline imbalance* & 0 & 4 & 18 & 6 & 8 & 12 & 7 & 6 & 10 & 6 & 5 & 9 \\
\hline downturn & 0 & 2 & 4 & 2 & 2 & 2 & 2 & 0 & 4 & 0 & 2 & 0 \\
\hline contract* & 0 & 0 & 2 & 4 & 2 & 0 & 2 & 0 & 0 & 0 & 2 & 0 \\
\hline stabilis* & 2 & 4 & 6 & 4 & 5 & 11 & 10 & 2 & 0 & 5 & 2 & 5 \\
\hline improve* & 17 & 23 & 16 & 19 & 11 & 12 & 22 & 26 & 27 & 18 & 25 & 22 \\
\hline eas* & 6 & 30 & 4 & 2 & 30 & 4 & 5 & 37 & 8 & 2 & 28 & 3 \\
\hline expan* & 6 & 7 & 3 & 21 & 8 & 7 & 12 & 5 & 12 & 10 & 6 & 5 \\
\hline sound & 0 & 2 & 6 & 4 & 5 & 13 & 0 & 2 & 2 & 2 & 0 & 9 \\
\hline robust & 23 & 21 & 24 & 44 & 30 & 31 & 19 & 34 & 32 & 32 & 38 & 29 \\
\hline favourable & 23 & 19 & 23 & 15 & 16 & 20 & 17 & 15 & 30 & 16 & 23 & 34 \\
\hline recover* & 6 & 5 & 7 & 0 & 0 & 5 & 10 & 6 & 7 & 5 & 62 & 7 \\
\hline upturn & 2 & 0 & 2 & 0 & 0 & 2 & 0 & 0 & 2 & 0 & 5 & 0 \\
\hline turmoil & 0 & 0 & 1 & 0 & 0 & 0 & 0 & 0 & 0 & 0 & 0 & 0 \\
\hline crisis & 0 & 0 & 1 & 21 & 0 & 0 & 0 & 0 & 0 & 0 & 0 & 0 \\
\hline optimis* & 0 & 2 & 8 & 0 & 0 & 2 & 5 & 2 & 4 & 0 & 3 & 0 \\
\hline pessimis* & 0 & 0 & 0 & 0 & 0 & 0 & 0 & 0 & 0 & 0 & 2 & 0 \\
\hline average negative & 20 & 20 & 17 & 19 & 17 & 15 & 19 & 13 & 16 & 15 & 19 & 14 \\
\hline average positive & 8 & 11 & 10 & 11 & 10 & 11 & 10 & 13 & 13 & 9 & 19 & 11 \\
\hline threshold negative & 17 & & & & & & & & & & & \\
\hline threshold positive & 11 & & & & & & & & & & & \\
\hline
\end{tabular}

\begin{tabular}{lllllllllll} 
jan-06 feb-06 & mar-06 & apr-06 & maj-06 & jun-06 & jul-06 & aug-06 & sep-06 & okt-06 & nov-06 & dec-06 \\
\hline
\end{tabular}

\begin{tabular}{|c|c|c|c|c|c|c|c|c|c|c|c|c|}
\hline slow* & 6 & 33 & 27 & 37 & 23 & 16 & 14 & 17 & 43 & 56 & 40 & 38 \\
\hline uncertain* & 37 & 35 & 51 & 23 & 26 & 46 & 17 & 32 & 34 & 21 & 27 & 37 \\
\hline weak* & 25 & 11 & 18 & 27 & 18 & 13 & 16 & 12 & 17 & 17 & 24 & 18 \\
\hline decelerat* & 4 & 4 & 4 & 0 & 0 & 2 & 0 & 2 & 8 & 6 & 0 & 0 \\
\hline adverse* & 2 & 0 & 1 & 2 & 0 & 0 & 3 & 0 & 3 & 4 & 1 & 1 \\
\hline risk* & 59 & 75 & 90 & 72 & 100 & 124 & 97 & 103 & 84 & 92 & 104 & 89 \\
\hline deteriorat* & 0 & 0 & 0 & 2 & 2 & 2 & 0 & 0 & 4 & 2 & 3 & 1 \\
\hline difficult* & 6 & 4 & 4 & 5 & 0 & 0 & 3 & 0 & 3 & 2 & 0 & 1 \\
\hline vigilant & 0 & 0 & 0 & 0 & 0 & 0 & 0 & 0 & 0 & 0 & 0 & 0 \\
\hline tension* & 0 & 18 & 3 & 0 & 0 & 0 & 0 & 31 & 5 & 4 & 6 & 0 \\
\hline imbalance* & 8 & 11 & 17 & 10 & 8 & 11 & 9 & 14 & 8 & 10 & 25 & 16 \\
\hline downturn & 0 & 2 & 0 & 3 & 2 & 1 & 2 & 0 & 7 & 4 & 0 & 2 \\
\hline contract* & 8 & 2 & 1 & 0 & 0 & 0 & 2 & 0 & 0 & 0 & 0 & 0 \\
\hline stabilis* & 2 & 2 & 1 & 0 & 2 & 7 & 0 & 2 & 3 & 4 & 7 & 1 \\
\hline improve* & 24 & 20 & 21 & 10 & 20 & 18 & 16 & 14 & 21 & 17 & 16 & 23 \\
\hline eas* & 2 & 31 & 3 & 12 & 41 & 4 & 3 & 24 & 5 & 8 & 28 & 5 \\
\hline expan* & 4 & 15 & 16 & 12 & 13 & 10 & 17 & 7 & 14 & 25 & 15 & 20 \\
\hline sound & 4 & 2 & 5 & 2 & 0 & 10 & 2 & 3 & 9 & 4 & 4 & 13 \\
\hline robust & 47 & 40 & 27 & 28 & 30 & 28 & 45 & 25 & 36 & 46 & 48 & 57 \\
\hline favourable & 16 & 29 & 47 & 28 & 34 & 27 & 31 & 20 & 37 & 19 & 21 & 31 \\
\hline recover* & 20 & 11 & 10 & 5 & 18 & 17 & 2 & 3 & 14 & 2 & 4 & 2 \\
\hline upturn & 0 & 2 & 1 & 3 & 0 & 3 & 2 & 0 & 5 & 0 & 0 & 1 \\
\hline turmoil & 0 & 0 & 0 & 0 & 0 & 0 & 0 & 0 & 0 & 0 & 1 & 1 \\
\hline crisis & 0 & 0 & 0 & 0 & 0 & 0 & 0 & 0 & 0 & 0 & 0 & 0 \\
\hline optimis* & 0 & 2 & 6 & 0 & 3 & 0 & 0 & 0 & 0 & 0 & 1 & 1 \\
\hline pessimis* & 0 & 0 & 0 & 0 & 0 & 0 & 2 & 2 & 3 & 0 & 0 & 0 \\
\hline average negative & 13 & 16 & 18 & 15 & 15 & 18 & 14 & 18 & 18 & 18 & 19 & 17 \\
\hline average positive & 12 & 15 & 14 & 10 & 16 & 12 & 12 & 10 & 14 & 13 & 15 & 15 \\
\hline threshold negative & 17 & & & & & & & & & & & \\
\hline threshold positive & 13 & & & & & & & & & & & \\
\hline
\end{tabular}




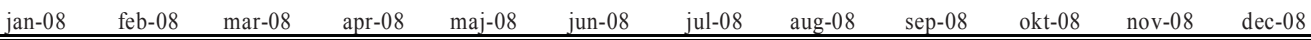

\begin{tabular}{|c|c|c|c|c|c|c|c|c|c|c|c|c|}
\hline slow* & 43 & 62 & 54 & 66 & 66 & 70 & 30 & 71 & 75 & 66 & 41 & 95 \\
\hline uncertain* & 21 & 34 & 27 & 37 & 37 & 29 & 27 & 20 & 30 & 53 & 42 & 67 \\
\hline weak* & 26 & 25 & 43 & 38 & 38 & 32 & 42 & 61 & 53 & 83 & 57 & 91 \\
\hline decelerat* & 3 & 0 & 5 & 2 & 2 & 7 & 0 & 5 & 15 & 6 & 1 & 11 \\
\hline adverse* & 1 & 1 & 7 & 2 & 2 & 2 & 13 & 10 & 10 & 14 & 9 & 10 \\
\hline risk* & 100 & 134 & 87 & 86 & 86 & 114 & 88 & 110 & 86 & 111 & 123 & 54 \\
\hline deteriorat* & 0 & 10 & 6 & 0 & 0 & 5 & 4 & 18 & 10 & 17 & 19 & 23 \\
\hline difficult* & 0 & 0 & 0 & 0 & 0 & 0 & 0 & 0 & 0 & 0 & 0 & 0 \\
\hline vigilant & 0 & 0 & 0 & 0 & 0 & 0 & 0 & 0 & 0 & 0 & 0 & 0 \\
\hline tension* & 38 & 14 & 27 & 25 & 25 & 27 & 57 & 65 & 49 & 63 & 49 & 50 \\
\hline imbalance* & 9 & 13 & 12 & 9 & 9 & 7 & 8 & 8 & 3 & 6 & 9 & 4 \\
\hline downturn & 1 & 3 & 1 & 2 & 2 & 3 & 3 & 1 & 2 & 2 & 1 & 12 \\
\hline contract* & 1 & 4 & 4 & 2 & 2 & 3 & 1 & 9 & 7 & 6 & 6 & 9 \\
\hline stabilis* & 9 & 8 & 17 & 3 & 3 & 29 & 10 & 4 & 13 & 8 & 3 & 14 \\
\hline improve* & 7 & 1 & 7 & 6 & 6 & 11 & 5 & 4 & 9 & 2 & 3 & 2 \\
\hline eas* & 1 & 18 & 3 & 2 & 2 & 7 & 4 & 3 & 5 & 9 & 9 & 8 \\
\hline expan* & 16 & 11 & 14 & 28 & 28 & 9 & 14 & 11 & 15 & 17 & 6 & 14 \\
\hline sound & 10 & 7 & 12 & 11 & 11 & 16 & 9 & 6 & 4 & 2 & 1 & 7 \\
\hline robust & 31 & 21 & 14 & 31 & 31 & 17 & 18 & 13 & 13 & 19 & 6 & 11 \\
\hline favourable & 15 & 7 & 20 & 15 & 15 & 21 & 10 & 9 & 9 & 3 & 1 & 3 \\
\hline recover* & 1 & 1 & 3 & 0 & 0 & 3 & 3 & 1 & 5 & 5 & 3 & 10 \\
\hline upturn & 0 & 0 & 0 & 0 & 0 & 1 & 1 & 0 & 0 & 0 & 0 & 1 \\
\hline turmoil & 35 & 55 & 44 & 35 & 35 & 30 & 18 & 28 & 9 & 20 & 53 & 43 \\
\hline crisis & 0 & 3 & 2 & 0 & 0 & 0 & 0 & 1 & 0 & 5 & 19 & 15 \\
\hline optimis* & 0 & 0 & 1 & 5 & 5 & 1 & 0 & 3 & 0 & 2 & 0 & 0 \\
\hline pessimis* & 0 & 3 & 0 & 0 & 0 & 0 & 0 & 0 & 1 & 0 & 0 & 1 \\
\hline average negative & 21 & 28 & 24 & 23 & 23 & 25 & 22 & 31 & 27 & 35 & 33 & 37 \\
\hline average positive & 9 & 8 & 9 & 10 & 10 & 11 & 8 & 5 & 7 & 7 & 3 & 7 \\
\hline threshold negative & 28 & & & & & & & & & & & \\
\hline threshold positive & 8 & & & & & & & & & & & \\
\hline
\end{tabular}

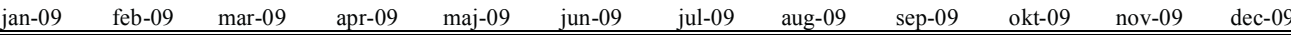

\begin{tabular}{|c|c|c|c|c|c|c|c|c|c|c|}
\hline slow* & 35 & 30 & 69 & 23 & 63 & 48 & 22 & 33 & 46 & 29 \\
\hline uncertain* & 31 & 25 & 46 & 31 & 19 & 44 & 54 & 124 & 70 & 45 \\
\hline weak* & 67 & 54 & 74 & 65 & 61 & 63 & 47 & 38 & 34 & 32 \\
\hline decelerat* & 2 & 3 & 16 & 13 & 26 & 11 & 14 & 18 & 15 & 8 \\
\hline adverse* & 3 & 11 & 12 & 8 & 11 & 12 & 9 & 7 & 4 & 4 \\
\hline risk* & 51 & 42 & 87 & 74 & 64 & 44 & 42 & 69 & 52 & 36 \\
\hline deteriorat* & 9 & 10 & 28 & 17 & 7 & 10 & 3 & 4 & 4 & 15 \\
\hline difficult* & 0 & 0 & 0 & 0 & 0 & 0 & 0 & 0 & 0 & 0 \\
\hline vigilant & 0 & 0 & 0 & 0 & 0 & 0 & 0 & 0 & 0 & 0 \\
\hline tension* & 41 & 19 & 21 & 14 & 10 & 8 & 5 & 7 & 9 & 0 \\
\hline imbalance* & 4 & 7 & 6 & 5 & 2 & 3 & 7 & 2 & 4 & 4 \\
\hline downturn & 6 & 11 & 22 & 18 & 18 & 28 & 20 & 4 & 18 & 13 \\
\hline contract* & 11 & 14 & 19 & 23 & 35 & 33 & 34 & 33 & 37 & 20 \\
\hline stabilis* & 3 & 6 & 5 & 21 & 7 & 14 & 36 & 12 & 11 & 45 \\
\hline improve* & 0 & 3 & 4 & 3 & 15 & 11 & 7 & 12 & 21 & 11 \\
\hline eas* & 4 & 3 & 6 & 3 & 10 & 12 & 7 & 6 & 5 & 5 \\
\hline expan* & 8 & 5 & 12 & 6 & 4 & 8 & 7 & 11 & 9 & 12 \\
\hline sound & 1 & 0 & 12 & 4 & 1 & 4 & 3 & 1 & 6 & 3 \\
\hline robust & 5 & 6 & 5 & 4 & 4 & 3 & 5 & 5 & 7 & 5 \\
\hline favourable & 1 & 2 & 3 & 0 & 1 & 4 & 0 & 2 & 6 & 4 \\
\hline recover* & 1 & 6 & 8 & 4 & 4 & 5 & 11 & 12 & 16 & 21 \\
\hline upturn & 0 & 0 & 0 & 0 & 0 & 0 & 1 & 1 & 3 & 1 \\
\hline turmoil & 20 & 25 & 29 & 31 & 14 & 26 & 28 & 19 & 12 & 4 \\
\hline crisis & 4 & 3 & 13 & 27 & 5 & 13 & 24 & 8 & 20 & 7 \\
\hline optimis* & 0 & 0 & 0 & 0 & 0 & 0 & 0 & 0 & 0 & 0 \\
\hline pessimis* & 0 & 0 & 1 & 0 & 0 & 1 & 1 & 2 & 1 & 4 \\
\hline average negative & 24 & 21 & 37 & 29 & 28 & 28 & 26 & 31 & 27 & 18 \\
\hline average positive & 3 & 3 & 6 & 5 & 5 & 7 & 9 & 7 & 9 & 12 \\
\hline threshold negative & 27 & & & & & & & & & \\
\hline threshold positive & 7 & & & & & & & & & \\
\hline
\end{tabular}




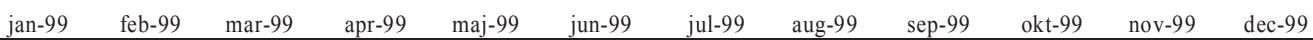

slow*

uncertain*

weak*

decelerat*

adverse*

risk*

deteriorat*

difficult*

vigilant

tension*

imbalance*

downturn

contract*

stabilis*

improve*

eas*

expan*

sound

robust

favourable

recover*

upturn

turmoil

crisis

optimis*

pessimis*

average negative

average positive

$\begin{array}{ll}55 & 35\end{array}$

$\begin{array}{llll}80 & 23 & 67 & 39\end{array}$

39
85

16
20

$14 \quad 10$

$\begin{array}{ll}10 & 12 \\ 24 & 17\end{array}$

23

85
13

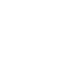

0

14

0

Months we used judgement for categorising

\begin{tabular}{ll}
\hline \hline June-July & 2000 \\
May & 2001 \\
February & 2000 \\
May & 2003 \\
October & 2004 \\
February-April & 2005 \\
June-July & 2006 \\
September-November & 2006 \\
\hline
\end{tabular}




\section{Appendix 3: Logit model estimation}

The dependent variable $S_{t}$ in equation 1 is a binary variable where $0=$ no stress and $1=$ stress.

Following the usual notation in a logit model, it is assumed that $\mathrm{S}_{\mathrm{t}}$ is an indirect observation of the continuous latent variable $\mathrm{S}_{\mathrm{t}}{ }^{*}$, where

$$
\mathrm{S}_{\mathrm{t}}^{*}=\alpha+\beta^{\prime} \mathrm{X}_{\mathrm{t}}+\varepsilon_{\mathrm{t}}
$$

$\mathrm{t}=1, \ldots \mathrm{T}$ and $\mathrm{X}_{\mathrm{t}}$ is the set of explanatory variables. Under the logistic distribution for $\varepsilon_{\mathrm{t}}$, the probability of being in stress can be written:

$$
\begin{aligned}
& P\left\langle S_{t}=1 \mid X_{t}, \alpha, \beta\right\rangle=\frac{\exp \left(\alpha+\beta^{\prime} X_{t}\right)}{1+\exp \left(\alpha+\beta^{\prime} X_{t}\right)} \\
& P\left\langle S_{t}=0 \mid X_{t}, \alpha, \beta\right\rangle=\frac{1}{1+\exp \left(\alpha+\beta^{\prime} X_{t}\right)}
\end{aligned}
$$

In the text the set of variables $\mathrm{X}$ consist of the level and the change indicators. The estimation results are presented in the following table, where we also show the results for different lengths of the period over which we compute the change, i.e. over 8,12 and 18 weeks:

\section{Table A1. Logit model estimation}

\begin{tabular}{llll} 
& FSI & FSI & FSI \\
\hline \hline Level & $\mathbf{4 , 5 2}$ & $\mathbf{4 , 3 0}$ & $\mathbf{4 , 2 1}$
\end{tabular}

Change 8 periods

0,05

Change 12 periods

0,09

Change 18 periods $\mathbf{0 , 0 7}$

McFadden R-squared

0,34 0,33

0,30

Note: figures in bold are significant at least at $5 \%$ significance level 


\section{Appendix 4. Loss function values}

Table A2. Loss function values for different $\theta$ 's.

\begin{tabular}{ccccccc}
$\mathbf{T}$ & theta $=\mathbf{0 . 3}$ & theta $=\mathbf{0 . 4}$ & theta $=\mathbf{0 . 5}$ & theta $=\mathbf{0 . 6}$ & theta $=\mathbf{0 . 7}$ & theta $=\mathbf{0 . 8}$ \\
\hline \hline 0,1 & 0,63 & 0,54 & 0,46 & 0,37 & 0,29 & 0,20 \\
0,2 & 0,33 & 0,29 & 0,25 & 0,21 & 0,17 & 0,13 \\
$\mathbf{0 , 3}$ & 0,21 & 0,19 & $\mathbf{0 , 1 7}$ & $\mathbf{0 , 1 6}$ & $\mathbf{0 , 1 4}$ & $\mathbf{0 , 1 2}$ \\
0,4 & 0,17 & $\mathbf{0 , 1 7}$ & 0,18 & 0,18 & 0,19 & 0,20 \\
0,5 & $\mathbf{0 , 1 6}$ & 0,18 & 0,20 & 0,22 & 0,25 & 0,27 \\
0,6 & 0,18 & 0,22 & 0,26 & 0,31 & 0,35 & 0,39 \\
0,7 & 0,21 & 0,26 & 0,31 & 0,37 & 0,42 & 0,47 \\
0,8 & 0,24 & 0,31 & 0,37 & 0,44 & 0,50 & 0,57 \\
0,9 & 0,25 & 0,33 & 0,41 & 0,48 & 0,56 & 0,64 \\
\hline \hline
\end{tabular}

Table A3. Loss function values for different $T$ 's $(\theta=0.5)$

window $=$ current period

\begin{tabular}{ccccccc}
$\mathbf{T}$ & $\begin{array}{c}\text { False } \\
\text { Alarm }\end{array}$ & $\begin{array}{c}\text { Missing } \\
\text { Stress }\end{array}$ & $\begin{array}{c}\text { Right } \\
\text { Signal } \\
\text { Stress }\end{array}$ & $\begin{array}{c}\text { Right } \\
\text { Signal no- } \\
\text { stress }\end{array}$ & $\begin{array}{c}\text { Number } \\
\text { Obs }\end{array}$ & $\begin{array}{c}\text { LOSS } \\
\text { theta=0.5 }\end{array}$ \\
\hline \hline 0,1 & 278 & 8 & 216 & 37 & 539 & 0,46 \\
0,2 & 142 & 11 & 213 & 173 & 539 & 0,25 \\
$\mathbf{0 , 3}$ & 84 & 20 & 204 & 231 & 539 & $\mathbf{0 , 1 8}$ \\
0,4 & 52 & 46 & 178 & 263 & 539 & 0,19 \\
0,5 & 33 & 70 & 154 & 282 & 539 & 0,21 \\
0,6 & 22 & 105 & 119 & 293 & 539 & 0,27 \\
0,7 & 18 & 130 & 94 & 297 & 539 & 0,32 \\
0,8 & 15 & 157 & 67 & 300 & 539 & 0,37 \\
0,9 & 8 & 177 & 47 & 307 & 539 & 0,41 \\
\hline \hline
\end{tabular}


Table A4. Loss function values for different T's

window $=2$ backward + current period + two forward

\begin{tabular}{ccccccc}
$\mathbf{T}$ & $\begin{array}{c}\text { False } \\
\text { Alarm }\end{array}$ & $\begin{array}{c}\text { Missing } \\
\text { Stress }\end{array}$ & $\begin{array}{c}\text { Right } \\
\text { Signal } \\
\text { Stress }\end{array}$ & $\begin{array}{c}\text { Rignal no- } \\
\text { stress }\end{array}$ & $\begin{array}{c}\text { Number } \\
\text { Obs }\end{array}$ & $\begin{array}{c}\text { LOSS } \\
\text { theta=0.5 }\end{array}$ \\
\hline \hline 0,1 & 274 & 8 & 216 & 37 & 535 & 0,46 \\
0,2 & 138 & 11 & 213 & 173 & 535 & 0,25 \\
$\mathbf{0 , 3}$ & 80 & 20 & 204 & 231 & 535 & $\mathbf{0 , 1 7}$ \\
0,4 & 48 & 46 & 178 & 263 & 535 & 0,18 \\
0,5 & 29 & 70 & 154 & 282 & 535 & 0,20 \\
0,6 & 19 & 105 & 119 & 292 & 535 & 0,26 \\
0,7 & 15 & 130 & 94 & 296 & 535 & 0,31 \\
0,8 & 13 & 157 & 67 & 298 & 535 & 0,37 \\
0,9 & 7 & 177 & 47 & 304 & 535 & 0,41 \\
\hline \hline
\end{tabular}

Table A5. Loss function values for different $T$ 's $(\theta=0.5)$

window $=$ current period + two forward

\begin{tabular}{ccccccc}
$\mathbf{T}$ & $\begin{array}{c}\text { False } \\
\text { Alarm }\end{array}$ & $\begin{array}{c}\text { Missing } \\
\text { Stress }\end{array}$ & $\begin{array}{c}\text { Right } \\
\text { Signal } \\
\text { Stress }\end{array}$ & $\begin{array}{c}\text { Right } \\
\text { Signal no- } \\
\text { stress }\end{array}$ & $\begin{array}{c}\text { Number } \\
\text { Obs }\end{array}$ & $\begin{array}{c}\text { LOSS } \\
\text { theta=0.5 }\end{array}$ \\
\hline \hline 0,1 & 274 & 8 & 216 & 37 & 535 & 0,46 \\
0,2 & 138 & 11 & 213 & 173 & 535 & 0,25 \\
$\mathbf{0 , 3}$ & 81 & 20 & 204 & 230 & 535 & $\mathbf{0 , 1 7}$ \\
0,4 & 50 & 46 & 178 & 261 & 535 & 0,18 \\
0,5 & 33 & 70 & 154 & 278 & 535 & 0,21 \\
0,6 & 22 & 105 & 119 & 289 & 535 & 0,27 \\
0,7 & 18 & 130 & 94 & 293 & 535 & 0,32 \\
0,8 & 15 & 157 & 67 & 296 & 535 & 0,37 \\
0,9 & 8 & 177 & 47 & 303 & 535 & 0,41 \\
\hline \hline
\end{tabular}


Table A6. FSI Success Ratio for different T's $(\theta=0.5)$

\begin{tabular}{ccccc} 
& \multicolumn{2}{c}{ right signal } & \multicolumn{2}{c}{ false signal } \\
\hline $\mathbf{T}$ & $\mathbf{S = 0}$ & $\mathbf{S = 1}$ & $\mathbf{S}=\mathbf{0}$ & $\mathbf{S = 1}$ \\
\hline \hline 0,1 & $7 \%$ & $40 \%$ & $51 \%$ & $1 \%$ \\
0,2 & $32 \%$ & $40 \%$ & $26 \%$ & $2 \%$ \\
$\mathbf{0 , 3}$ & $\mathbf{4 3 \%}$ & $\mathbf{3 8 \%}$ & $\mathbf{1 5 \%}$ & $\mathbf{4 \%}$ \\
0,4 & $49 \%$ & $33 \%$ & $9 \%$ & $9 \%$ \\
0,5 & $53 \%$ & $29 \%$ & $5 \%$ & $13 \%$ \\
0,6 & $55 \%$ & $22 \%$ & $4 \%$ & $20 \%$ \\
0,7 & $55 \%$ & $18 \%$ & $3 \%$ & $24 \%$ \\
0,8 & $56 \%$ & $13 \%$ & $2 \%$ & $29 \%$ \\
0,9 & $57 \%$ & $9 \%$ & $1 \%$ & $33 \%$ \\
\hline \hline
\end{tabular}

Note: the success ratio is computed here as in Table 8.

Table A7. FSI's Success Ratio for different T's $(\boldsymbol{\theta}=\mathbf{0 . 5})$

right signal

\begin{tabular}{ccccc} 
& \multicolumn{2}{c}{ right signal } & \multicolumn{2}{c}{ false signal } \\
\hline $\mathbf{T}$ & $\mathbf{S = 0}$ & $\mathbf{S = 1}$ & $\mathbf{S = 0}$ & $\mathbf{S = 1}$ \\
\hline \hline 0,1 & $12 \%$ & $96 \%$ & $88 \%$ & $4 \%$ \\
0,2 & $56 \%$ & $95 \%$ & $44 \%$ & $5 \%$ \\
$\mathbf{0 , 3}$ & $\mathbf{7 4 \%}$ & $\mathbf{9 1 \%}$ & $\mathbf{2 6 \%}$ & $\mathbf{9 \%}$ \\
0,4 & $85 \%$ & $79 \%$ & $15 \%$ & $21 \%$ \\
0,5 & $91 \%$ & $69 \%$ & $9 \%$ & $31 \%$ \\
0,6 & $94 \%$ & $53 \%$ & $6 \%$ & $47 \%$ \\
0,7 & $95 \%$ & $42 \%$ & $5 \%$ & $58 \%$ \\
0,8 & $96 \%$ & $30 \%$ & $4 \%$ & $70 \%$ \\
0,9 & $98 \%$ & $21 \%$ & $2 \%$ & $79 \%$ \\
\hline \hline
\end{tabular}

Note: the success ratio is computed as the number of right (false) signals over the total number of periods in which a right (false) signal should have been issued. 
Table A8. FSI_anecdotal's Success Ratio for different T's $(\theta=0.5)$

\begin{tabular}{ccccc} 
& \multicolumn{2}{c}{ right signal } & \multicolumn{2}{c}{ false signal } \\
\hline $\mathbf{T}$ & $\mathbf{S = 0}$ & $\mathbf{S = 1}$ & $\mathbf{S = 0}$ & $\mathbf{S = 1}$ \\
\hline \hline 0,1 & $1 \%$ & $43 \%$ & $55 \%$ & $1 \%$ \\
0,2 & $6 \%$ & $40 \%$ & $50 \%$ & $4 \%$ \\
$\mathbf{0 , 3}$ & $\mathbf{2 6 \%}$ & $\mathbf{3 6 \%}$ & $\mathbf{2 9 \%}$ & $\mathbf{9 \%}$ \\
0,4 & $42 \%$ & $32 \%$ & $14 \%$ & $12 \%$ \\
0,5 & $50 \%$ & $29 \%$ & $5 \%$ & $16 \%$ \\
0,6 & $53 \%$ & $19 \%$ & $3 \%$ & $25 \%$ \\
0,7 & $54 \%$ & $14 \%$ & $1 \%$ & $30 \%$ \\
0,8 & $55 \%$ & $10 \%$ & $1 \%$ & $35 \%$ \\
0,9 & $56 \%$ & $6 \%$ & $0 \%$ & $39 \%$ \\
\hline \hline
\end{tabular}

Note: the success ratio is computed here as in Table 8 .

Table A9. FSI_anecdotal's Success Ratio for different T's $(\theta=0.5)$

\begin{tabular}{ccccc} 
& \multicolumn{2}{c}{ right signal } & \multicolumn{2}{c}{ false signal } \\
\hline $\mathbf{T}$ & $\mathbf{S = 0}$ & $\mathbf{S = 1}$ & $\mathbf{S = 0}$ & $\mathbf{S = 1}$ \\
\hline \hline 0,1 & $2 \%$ & $107 \%$ & $98 \%$ & $3 \%$ \\
0,2 & $10 \%$ & $100 \%$ & $89 \%$ & $9 \%$ \\
$\mathbf{0 , 3}$ & $\mathbf{4 4 \%}$ & $\mathbf{8 8 \%}$ & $\mathbf{5 3 \%}$ & $\mathbf{2 0 \%}$ \\
0,4 & $69 \%$ & $80 \%$ & $25 \%$ & $28 \%$ \\
0,5 & $83 \%$ & $71 \%$ & $10 \%$ & $36 \%$ \\
0,6 & $88 \%$ & $48 \%$ & $5 \%$ & $57 \%$ \\
0,7 & $90 \%$ & $36 \%$ & $2 \%$ & $68 \%$ \\
0,8 & $90 \%$ & $24 \%$ & $2 \%$ & $79 \%$ \\
0,9 & $92 \%$ & $15 \%$ & $0 \%$ & $87 \%$ \\
\hline \hline
\end{tabular}

Note: the success ratio is computed as the number of right (false) signals over the total number of periods in which a right (false) signal should have been issued. 
Table A10. Relative Success Ratio for different T's $(\theta=0.5)$

\begin{tabular}{ccrcr} 
& right signal & \multicolumn{3}{c}{ false signal } \\
\hline $\mathbf{T}$ & $\mathbf{S = 0}$ & $\mathbf{S = 1}$ & $\mathbf{S = 0}$ & $\mathbf{S}=\mathbf{1}$ \\
\hline \hline 0,1 & $740 \%$ & $93 \%$ & $94 \%$ & $133 \%$ \\
0,2 & $541 \%$ & $99 \%$ & $52 \%$ & $50 \%$ \\
$\mathbf{0 , 3}$ & $\mathbf{1 6 4 \%}$ & $\mathbf{1 0 7 \%}$ & $\mathbf{5 1 \%}$ & $\mathbf{4 3 \%}$ \\
0,4 & $118 \%$ & $103 \%$ & $65 \%$ & $70 \%$ \\
0,5 & $105 \%$ & $101 \%$ & $100 \%$ & $82 \%$ \\
0,6 & $103 \%$ & $116 \%$ & $136 \%$ & $78 \%$ \\
0,7 & $102 \%$ & $122 \%$ & $214 \%$ & $81 \%$ \\
0,8 & $102 \%$ & $131 \%$ & $260 \%$ & $84 \%$ \\
0,9 & $102 \%$ & $147 \%$ & $\infty$ & $86 \%$ \\
\hline \hline
\end{tabular}

Note: the success ratio is computed here as in Table 8. 


\section{Appendix 6. Forward FSI (FFSI)}

Chart A1. The FFSI with different periods of forewarning

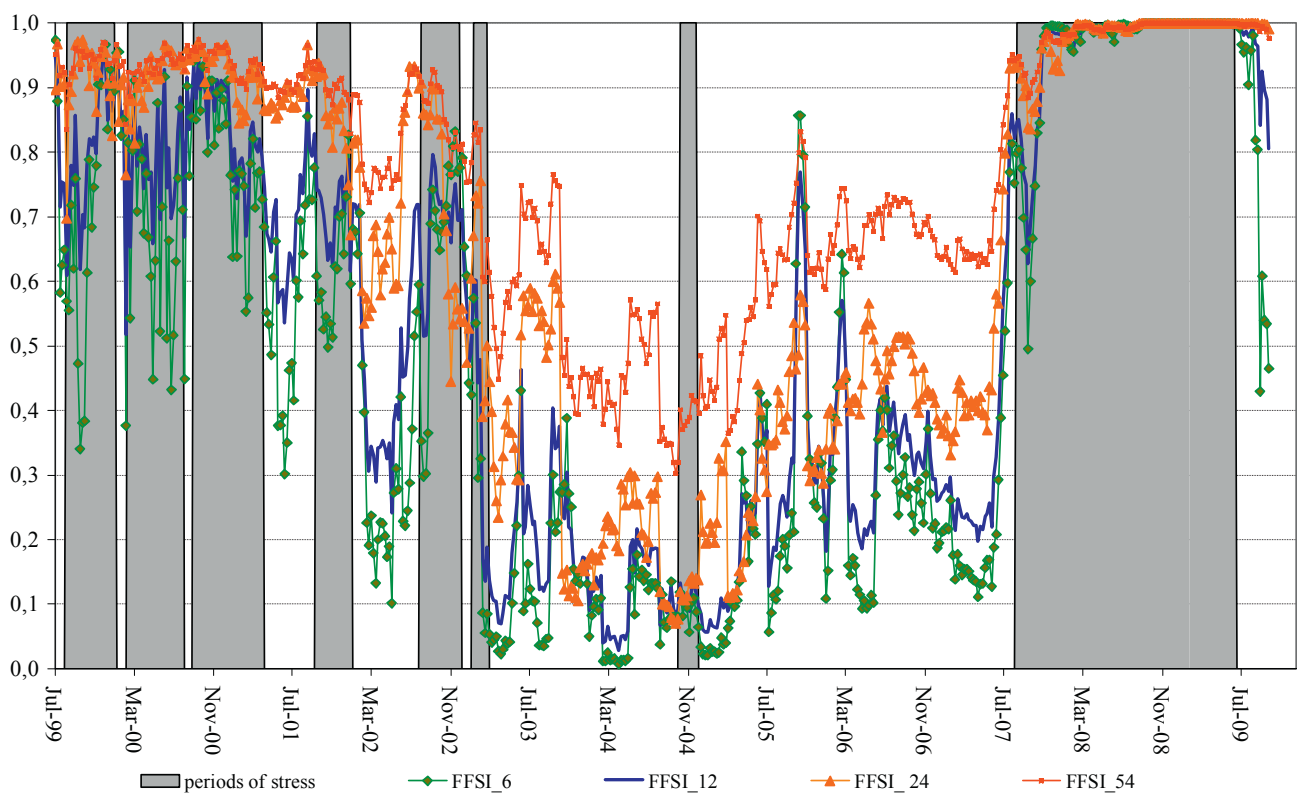

Table A11. Logit model

\begin{tabular}{lcccc} 
& $\begin{array}{l}\text { FFSI 6 } \\
\text { periods }\end{array}$ & $\begin{array}{l}\text { FFSI 12 } \\
\text { periods }\end{array}$ & $\begin{array}{l}\text { FFSI 24 } \\
\text { periods }\end{array}$ & $\begin{array}{l}\text { FFSI 54 } \\
\text { periods }\end{array}$ \\
\hline \hline Level & $\mathbf{6 , 4 8}$ & $\mathbf{6 , 4 3}$ & $\mathbf{7 , 6 1}$ & $\mathbf{5 , 4 9}$ \\
Change & $\mathbf{0 , 1 4}$ & $\mathbf{0 , 0 8}$ & $-0,02$ & 0,01 \\
\hline & & & & \\
McFadden R-squared & 0,42 & 0,38 & 0,37 & 0,24 \\
\hline \hline Note: figures in bold are significant at least at 5\% significance level & &
\end{tabular}


Table A12. FFSI's Loss function values for different T's $(\theta=0.5)$

window $=3$ backward + current period

\begin{tabular}{ccccccc} 
& False & Missing & $\begin{array}{c}\text { Right } \\
\text { Signal }\end{array}$ & \multicolumn{2}{c}{ Right } & Signal no- \\
T & Alarm & Stress & Stress & stress & Obs & $\begin{array}{c}\text { LOSS } \\
\text { theta=0.5 }\end{array}$ \\
\hline \hline 0,1 & 176 & 2 & 234 & 0 & 412 & 0,50 \\
0,2 & 148 & 25 & 211 & 28 & 412 & 0,47 \\
0,3 & 124 & 36 & 200 & 52 & 412 & 0,43 \\
0,4 & 82 & 48 & 188 & 94 & 412 & 0,33 \\
0,5 & 32 & 49 & 187 & 144 & 412 & 0,19 \\
$\mathbf{0 , 6}$ & 9 & 72 & 164 & 167 & 412 & 0,18 \\
0,7 & 6 & 87 & 149 & 170 & 412 & 0,20 \\
0,8 & 5 & 94 & 142 & 171 & 412 & 0,21 \\
0,9 & 1 & 179 & 57 & 175 & 412 & 0,38 \\
\hline \hline
\end{tabular}

Table A13. FFSI's Loss function values for different $\theta$ 's window $=3$ backward + current period

\begin{tabular}{ccccccc}
$\mathbf{T}$ & theta=0.3 & theta $=\mathbf{0 . 4}$ & theta $=\mathbf{0 . 5}$ & theta $=\mathbf{0 . 6}$ & theta=0.7 & theta $=\mathbf{0 . 8}$ \\
\hline \hline 0,1 & 0,70 & 0,60 & 0,50 & 0,41 & 0,31 & 0,21 \\
0,2 & 0,62 & 0,55 & 0,47 & 0,40 & 0,33 & 0,25 \\
0,3 & 0,54 & 0,48 & 0,43 & 0,37 & 0,32 & 0,26 \\
0,4 & 0,39 & 0,36 & 0,33 & 0,31 & 0,28 & 0,26 \\
0,5 & 0,19 & 0,19 & 0,19 & 0,20 & 0,20 & 0,20 \\
0,6 & 0,13 & 0,15 & 0,18 & 0,20 & 0,23 & 0,25 \\
0,7 & 0,13 & 0,17 & 0,20 & 0,23 & 0,27 & 0,30 \\
0,8 & 0,14 & 0,18 & 0,21 & 0,25 & 0,29 & 0,32 \\
0,9 & 0,23 & 0,31 & 0,38 & 0,46 & 0,53 & 0,61 \\
\hline \hline
\end{tabular}




\section{References}

Alessi, L., and Detken, C., (2009), “"Real time” early warning indicators for costly asset price boom/bust cycles: a role for global liquidity”, ECB Working Papers Series, No. 1039.

Barberis, N., and Thaler, R., (2003), "A survey of behavioural finance", Handbook of the Economics of Finance, Elsevier Science B.V..

Berg, A., and Coke, R., (2004), "Autocorrelation-Corrected Standard Errors in Panel Probits: An Application to Currency Crisis Prediction", IMF Working Papers No 39.

Berg, A., and Patillo, C., (1999), "Predicting currency crises: The indicators approach and an alternative”, Journal of International Money and Finance, Elsevier, vol. 18(4).

Bligh, M., and Hess, G., (2009), "A quantitative assessment of the qualitative aspects of Chairman Greenspan's communications", downloadable at http://www.wlu.ca/viessmann/CBCOM/Hess.pdf.

Brooks, C., (2008), Introductory Econometrics for Finance, Cambridge University Press.

Bussière, M., and Fratzcher, M., (2006), "Towards a new early warning system of financial crises," Journal of International Money and Finance, Elsevier, vol. 25(6).

Bussière, M., (2007), "Balance of payment crises in emerging markets: how early were the "early” warning signals?", ECB Working Papers Series , No 713.

Cardarelli, R., Elekdag, S., Lall, S., (2009), "Financial stress, downturns and recoveries", IMF Working Papers Series, No 100.

Chulia, H., Climent, F., Soriano, P., Torro, H., (2009), "Volatility transmission patterns and terrorist attacks", Quantitative Finance, vol. 9 (5).

De Grauwe, P., and Grimaldi M., (2006), The Exchange Rate in a Behavioral Finance Framework, Princeton University Press.

The Economist (2000a), "Frankfurt's dot.com dreams", March $30^{\text {th }} 2000$.

The Economist (2000b), "After the gold rush. Have the markets really punctured the dot.com bubble?“, April 20th 2000.

The Economist, (2002), “A guide to corporate scandals", July 15 2002.

The Economist, (2002), "Corporate America's woes, continued”, November $28^{\text {th }} 2002$.

The Economist, (2004), “The crude art of policymaking”, June 10 2004.

The Economist, (2004), "Frozen by oil-price fears", October $21^{\text {st }} 2004$.

Estrella, A., and Mishkin, F.S., (1998), "The yield curve as a predictor of US-recessions," Current Issues in Economics and Finance (2) 7. 
Fuertes, A.M., and Kalotychou, E., (2004), "Forecasting sovereign default using panel models: A comparative analysis", Computing in Economics and Finance, No 231, Society for Computational Economics.

Gerlach, S., (2004), "Interest rate setting by the ECB: words and deeds", CEPR, Discussion Paper 4775.

Gilovich, T., Valone, R., and Tversky, A., (1985), "The Hot Hand in Basketball: On the Misperception of Random Sequences”, Cognitive Psychology, vol. 17, no. 3 (July):295-314.

Goldstein, M., Kaminsky, G., and Reinhart, C., (2000), Assessing Financial Vulnerability; an Early Warning System for Emerging markets, Institute for International Economics.

Hahn, E. and Skudelny, F., (2008), "Early estimates of euro area real GDP growth: A bottomup approach from the production side," ECB Working Paper Series, No 975.

Kaminsky, G., (1999), "Currency and Banking Crises - The Early Warnings of Distress", IMF Working Papers, No178.

Kaminsky, G., Lizondo, S., and Reinhart, C., (1998), "Leading Indicators of Currency Crisis", IMF Staff Papers, No 45.

Illing, M., and Liu, Y., (2006), "Measuring financial stress in a developed country: An application to Canada", Journal of Financial Stability, Vol. 2(3).

James, J., (2003), "Simple trend-following strategies in currency trading", Quantitative Finance, Vol.3(4).

Lam L., Fung, L., and Yu, I., (2008) "Comparing Forecast Performance of Exchange Rate Models", HKMA.

Lestano, Jacobs, J., Kuper G., (2003), "Indicators of financial crises do work! An earlywarning system for six Asian countries", CCSO Working Paper, University of Groningen, CCSO Centre for Economic Research.

Lucca, D., and Trebbi, F., (2009), "Measuring central bank communication: an automated approach with application to FOMC statements", NBER Working Paper, No 15367.

Mandelbrot, B. B. (2008), The (mis)behaviour of markets, Profile books: London.

Nelson, W., and Perli, R., (2006), "Selected Indicators of Financial Stability" available at: http://www.ecb.int/events/pdf/conferences/jcbrconf4/Perli.pdf

Pindyck, R. S., and Rubinfeld, D. L., 1991, Econometric models and economic forecasts, 3rd ed., New York: McGraw-Hill, Inc.

Rosa, C., and Verga, G., (2005), "Is ECB communication effective?" Centre for Economic Performance, Discussion Paper No. 0682.

Shefrin, H., (2005), A Behavioral Approach to Asset Pricing, Burlington, MA: Elsevier Academic Press. 
Shiller, R., (2000), Irrational Exuberance, Princeton University Press.

Shleifer, A., (2000), Inefficient Markets: An Introduction to Behavioral Finance, OUP: Oxford.

Taleb, N., (2007), The Black Swan: The Impact of the Highly Improbable, Random House.

Taylor, J., and Williams, J.C., (2008), “A Black Swan in the Money Market”, NBER Working Paper, No 13943. 
